Estudios Constitucionales, Año 8, No 2, 2010, pp. 125 - 166.

ISSN 0718-0195

Centro de Estudios Constitucionales de Chile Universidad de Talca

"Los derechos sociales de prestación en la jurisprudencia chilena" José Ignacio Martínez Estay

\title{
LOS DERECHOS SOCIALES DE PRESTACIÓN EN LA JURISPRUDENCIA CHILENA
}

\author{
THE SOCIAL RIGHTS IN THE CHILEAN JURISPRUDENCE
}

\author{
José Ignacio Martínez Estay* \\ Profesor de Derecho Constitucional \\ Universidad de los Andes \\ jimartinez@uandes.cl
}

RESUMEN: Parte importante de los derechos sociales consisten en prestaciones. Desde el punto de vista jurídico ello parece ser una limitante para su garantía y satisfacción, pues dependen de los recursos económicos de que disponga el Estado. Por eso, lo usual es que si se constitucionalizan no llevan aparejada una garantía jurisdiccional. Asi ocurre en la Constitución chilena. Dicha limitación se ve ratificada por la jurisprudencia de la Corte Suprema, que reiteradamente ha negado lugar a recursos de protección en que se intentaba la tutela de derechos sociales consistentes en prestaciones, vinculándolos a algún derecho protegido jurisdiccionalmente. Pero la reciente jurisprudencia del Tribunal Constitucional respecto del derecho a la protección de la salud y del derecho a la seguridad social contradice lo anterior, atribuyéndole a los derechos sociales consistentes en prestaciones el mismo valor que el de los demás derechos y libertades.

ABSTRACT: Most of the social rights consist in social benefits. From the legal point of view, this is an important constraint to its protection and satisfaction, because they depend on the economic resources available by the State. Consequently, when a Constitution recognizes those rights usually does not give the possibility of judicial protection. That is what happens in the Chilean Constitution. The jurisprudence of the Supreme Court has confirmed that social benefits are not enforceable in Courts, even when they are associated to traditional rights and freedoms. However, the Constitutional Court's recent jurisprudence regarding the rights to health protection and to social security contradicts this, attributing to social rights the same value as other rights and freedoms.

PALABRAS CLAVE: Derechos fundamentales. Derechos sociales. Jurisprudencia chilena.

KEY WORDS: Fundamental rights. Social rights. Chilean Jurisprudence.

\footnotetext{
* Doctor en Derecho por la Universidad de Santiago de Compostela, España; Catedrático Jean Monnet de Derecho Público de la Unión Europea. Artículo recibido el 3 de junio de 2010 y aprobado el 22 de septiembre de 2010.
} 


\section{ORIGEN Y EVOLUCIÓN DE LOS DERECHOS SOCIALES ${ }^{1}$}

A mediados del siglo XIX comienzan a plantearse las primeras demandas sociales, y a surgir los primeros movimientos obreros. En Francia el deseo de transformar el orden liberal dio paso a la revolución de 1848, cuyo carácter social quedó reflejado en sus reivindicaciones: asegurar condiciones mínimas de existencia, derecho al trabajo, derecho a la instrucción, y nacionalización de la banca, minas y ferrocarriles.

Uno de los frutos más importantes de esta revolución fue la Constitución de 4 de noviembre de 1848, cuyo texto contenía algunas disposiciones que eran fiel reflejo del espíritu revolucionario. En ella se consagraban deberes del Estado que apuntaban a mejorar las condiciones económicas, sociales y culturales de los ciudadanos, en especial de los más desvalidos. La consagración de derechos sociales en esta Constitución fue el primer paso hacia un nuevo enfoque del constitucionalismo, acorde con la idea de reformar la estructura liberal de la sociedad: el constitucionalismo social.

El pleno desarrollo de esta tendencia constitucional sólo comienza a partir de la Primera Guerra Mundial. Durante esa época, se generaliza la percepción de que resulta indispensable el compromiso del Estado en favor de una mayor igualdad material. Los derechos sociales se incorporan a los tradicionales listados de derechos de las Constituciones, las que, además, imponen al Estado el deber de actuar en favor de la igualdad material.

Paradigma de este modelo constitucional son las Constituciones mexicana de 1917, y en especial la alemana de 1919. El modelo propuesto por ambas fue recogido por la Constitución española de 1931. A dichas constituciones se suma la Constitución irlandesa de 1937. Más tarde, después de la Segunda Guerra Mundial, las Constituciones italiana de 1946, portuguesa de 1976 y española de 1978, entre otras, incorporan también largos listados de derechos sociales. Y como se sabe, nuestra Constitución no sólo reconoce derechos clásicos o liberales, sino que también derechos sociales, a saber, el derecho a vivir en un medio ambiente libre de contaminación (art. 19 No 8), el derecho a la protección de la salud (art. 19 No 9), el derecho a la educación (art. 19 No 10), el derecho a una remuneración justa (art. 19 No 16 inc. 2o), el derecho a la negociación colectiva (art. 19 No 16 inc. $5^{\circ}$ ), el derecho a la huelga (art. 19 No 16 inc. $5^{\circ}$ ), el derecho a la seguridad social (art. 19 No 18) y el derecho a la sindicación (art. 19 No 19).

A su vez, en nuestro continente son varias las constituciones que los han incorporado a sus listados de derechos. Así, junto a la mexicana, pueden citarse a

\footnotetext{
${ }^{1}$ Sobre el origen y evolución del constitucionalismo social y los derechos sociales ver MARTínEZ (1997), pp. 21-58.
} 
modo meramente ejemplar las constituciones de Argentina, Costa Rica, Colombia y Perú. El Capítulo I de la Constitución de México ("De las garantías individuales") del Título I, reconoce en su artículo 3 el derecho a recibir educación. El artículo 4 proclama los derechos de los pueblos indígenas, el derecho a decidir el número de hijos, el derecho a la salud, el derecho a un medioambiente adecuado y los derechos de los niños. A su vez, en el Título VI ("Del trabajo y de la previsión social"), el artículo 123 reconoce el derecho a un trabajo digno y a determinadas condiciones de trabajo. Por su parte, la Constitución argentina consagra una serie de derechos de los trabajadores, incluidos los colectivos laborales, así como el derecho a la seguridad social (art. 14 bis, inserto en la Primera Parte, Capítulo Primero, sobre "Declaraciones, derechos y garantías"). Reconoce también el derecho a un ambiente sano y equilibrado y los derechos de los consumidores (Primera Parte, Capítulo Segundo, sobre "Nuevos derechos y garantías", arts. 41 y 42, respectivamente).

Por su parte, la Constitución de Costa Rica reconoce, entre otros, el derecho a un ambiente sano; el derecho a la protección de la familia, de la madre, del niño, del anciano y del enfermo desvalido; la igualdad entre hijos independientemente de la filiación; el derecho a saber quiénes son los padres de uno; el derecho al trabajo y el derecho a un salario mínimo y a determinadas condiciones de trabajo; derechos colectivos laborales; el deber del Estado de promover "la construcción de viviendas populares y creará el patrimonio familiar del trabajador", y de velar "por la preparación técnica y cultural de los trabajadores", y el derecho a la seguridad social (artículos 50 al 74, incluidos en el Capítulo Único del Título V).

En la Constitución colombiana sus artículos 42 al 77 (Capítulo II del Título II sobre los "Derechos, las garantías y los deberes") se refieren a los derechos sociales, económicos y culturales. Entre otros, se cuentan los derechos colectivos laborales; derechos de los niños; derechos de los adolescentes; derecho a una vivienda digna; derecho a la seguridad social; derecho a la atención en salud; derecho a practicar deportes y a la recreación; derecho a la educación; derecho de acceso a la cultura ${ }^{2}$. A su vez, el Capítulo III, sobre los derechos colectivos y del ambiente (arts. 7882), reconoce el derecho a un medioambiente sano ${ }^{3}$.

\footnotetext{
${ }^{2}$ Junto con ello se reconocen facultades que no consisten en prestaciones: la libertad para buscar el conocimiento y para la expresión artística, la libertad e independencia para desempeñar la actividad periodística, el derecho a acceder a documentos públicos, la igualdad de oportunidades para acceder al espectro electromagnético.

${ }^{3}$ En este Capítulo se reconocen, además, el derecho a que la ley regule el control de calidad de bienes y servicios ofrecidos y prestados a la comunidad; la prohibición de la fabricación, importación, posesión y uso de armas químicas, biológicas y nucleares, así como la introducción al territorio nacional de residuos
} 
Asimismo, en la Constitución peruana los artículos 4 al 29 (Capítulo II del Título I) se refieren a los derechos sociales y económicos. Entre otros, se reconocen el deber del Estado de proteger al niño, al adolescente, a la madre y al anciano en situación de abandono; derecho a la protección de la salud; derecho a la seguridad social; derecho a la educación; el derecho al trabajo y a determinadas condiciones de trabajo, y los derechos colectivos laborales.

La constitucionalización de derechos sociales ha sido acompañada también por la incorporación de éstos en instrumentos internacionales, como el Pacto Internacional de Derechos Económicos, Sociales y Culturales de $1966^{4}$, o el Protocolo Adicional a la Convención Americana sobre Derechos Humanos en Materia de Derechos Económicos, Sociales y Culturales 5 .

\section{Derechos sociales y Estados del Bienestar}

Resulta llamativo que los Estados que han contado con los sistemas de asistencia social más importantes del mundo no han considerado esta materia una cuestión constitucional $^{6}$. Y si alguno ha incluido derechos sociales en su Constitución, ha quedado claro que cuando consisten en prestaciones sólo adquieren eficacia una vez desarrollados infraconstitucionalmente. Tal es el caso de Gran Bretaña, Suecia, Francia y Canadá.

Gran Bretaña ha mantenido un sistema de asistencia social desde comienzos del siglo XVII, en que surgen las primeras "leyes de pobres". A comienzos del siglo XX elaboró un sistema de seguros de enfermedad y de cesantía, y durante la década de los 40 del siglo XX impulsó el desarrollo de su hasta hoy vigente sistema de seguridad social. Dicho sistema está basado en las propuestas del Informe Beveridge (1942), que además sirvió de inspiración a las reformas en la seguridad social de muchos países. La adopción de aquel sistema es, a su vez, el origen de la expresión Welfare State. Y en Gran Bretaña todos estos temas tienen en común el hecho de que no tienen carácter constitucional, pues no forman parte de la Constitución ni del Derecho Constitucional.

nucleares y desechos tóxicos y el deber del Estado velar por la protección de la integridad del espacio público y por su destinación al uso común.

${ }^{4}$ Este Pacto fue suscrito por Chile el 16 de septiembre de 1969, y promulgada en el Diario Oficial de 29 de mayo de 1989.

${ }^{5}$ Chile no es parte de este Protocolo. En todo caso, el art. 26 de la Convención Americana sobre Derechos Humanos contempla una cláusula mediante la cual los Estados parte se comprometen a desarrollar los derechos sociales "en la medida de los recursos disponibles, por vía legislativa u otros medios apropiados".

${ }^{6} \mathrm{Al}$ respecto ver MARTíneZ (1997), 59-66. 
A su vez, Suecia comenzó a implementar medidas de asistencia y seguridad social desde comienzos de la pasada centuria, con la adopción de un sistema de pensiones para la vejez y de uno de cesantía, entre otras medidas. Más tarde, en la década del 30 del siglo pasado, se desarrolla y consolida uno de los modelos de Estado de Bienestar más avanzados y admirados. Y al igual que en Gran Bretaña, todos esos temas no son cuestiones constitucionales: no son parte de la Constitución ni del Derecho Constitucional.

Francia también cuenta con un admirado sistema de asistencia social, que conforma el denominado État-providence. Sin embargo, Francia sí tiene derechos sociales en su Constitución, aunque, al igual que los derechos clásicos, no forman parte de su articulado sino que de su preámbulo. En esta parte se proclama la adhesión del pueblo francés a los derechos consagrados en la Declaración de 1789, y a los del preámbulo de la Constitución de 1946. Y si bien el Consejo Constitucional francés ha entendido que aquellos instrumentos tienen rango constitucional, a la vez ha señalado que no todos los derechos tienen la misma eficacia.

Algunos se bastan a sí mismos y resultan directamente aplicables. Este es el caso de la práctica totalidad de los derechos clásicos proclamados en la Declaración de 1789 y en el Preámbulo de la Constitución de 1946. A ellos se agregan algunos derechos sociales que no suponen prestaciones, como el de huelga. Pero hay otros derechos que requieren la intervención posterior del legislador, y mientras ello no ocurra no son justiciables: sólo tienen el carácter de directivas o promesas desprovistas de todo carácter jurídico obligatorio. Esa es la situación de todos los derechos sociales que consisten en prestaciones, que están contemplados en el Preámbulo de la Constitución de 1946, como el derecho al trabajo.

En todo caso, el Consejo Constitucional ha resuelto también que puede controlar la constitucionalidad de las leyes que desarrollan derechos sociales del preámbulo. Pero ello no altera el carácter meramente legal del État-providence. Por eso, mientras no exista desarrollo legislativo, los derechos sociales que consistan en prestaciones no son más que aspiraciones o directrices políticas.

Por su parte, la Constitución de Canadá no tiene un listado de derechos sociales, ni cuenta con ningún precepto que proclame de manera expresa el Estado Social o el Welfare State. Sólo a partir de 1982 es posible encontrar alguna referencia tangencial a estas materias, en la Carta Canadiense de Derechos y Libertades, uno de los documentos que conforman la Constitución de ese país. Su artículo 15, después de proclamar el principio de igualdad (apartado 1), señala que tal principio es sin perjuicio de las leyes, programas o actividades destinadas a mejorar las condiciones de individuos o grupos desventajados (apartado 2).

A su vez, el artículo 36 encomienda al Parlamento y Gobierno de Canadá, así como a los parlamentos y gobiernos provinciales, llevar a cabo las medidas que 
permitan una auténtica igualdad de oportunidades. También encarga al Parlamento y al Gobierno canadienses respetar el "principio de igualación de pagos" (principle of making equalization payments), a fin de que los gobiernos provinciales tengan los medios suficientes "para proveer servicios públicos de niveles razonablemente comparables con razonables niveles impositivos" (to provide reasonably comparable levels of public services at reasonably comparable levels of taxation) (apartado 2). Sin embargo, esos preceptos no crean nada nuevo, pues Canadá desarrolló un Welfare State mucho antes de 1982, a la par con el Reino Unido, y comparable con el de éste. De ahí que pueda afirmarse que "a la hora de construir una red asistencial fue más importante la cultura política (de asistencia social) que el texto constitucional (clásico y liberal)" 7 .

En resumen, los países que han mantenido los modelos de Estado de Bienestar más envidiados del mundo no han hecho de ello una cuestión constitucional, y no cuentan con derechos sociales en sus magnas cartas. Sin embargo, sus políticas sociales son mejores en cantidad y calidad que la de muchos Estados que han constitucionalizado estos derechos.

\section{DeRECHOS SOCIALES Y PRESTACIONES}

Si se analizan las constituciones que consagran derechos sociales, puede comprobarse que la mayor parte de éstos consisten, fundamentalmente, en prestaciones. Así fueron concebidos por el constituyente francés de 1848, y así también recogidos hasta nuestros días por los países que los han constitucionalizado y por los tratados internacionales que los han reconocido. Pero nótese que no hemos afirmado que estos derechos sean prestaciones, ni hemos utilizado esta expresión como sinónimo de aquéllos. Esto se debe a que determinados derechos sociales no consisten en prestaciones. De hecho, entre éstos, los constituyentes suelen incluir derechos no consistentes en prestaciones. Es el caso de los derechos relacionados con el ámbito laboral, como el derecho a la huelga, el derecho a la negociación colectiva y el derecho de sindicación.

Estos derechos son manifestaciones de derechos y libertades clásicos, que operan en el ámbito de las relaciones laborales. Así, el derecho de sindicación no es sino manifestación del derecho de asociación, y los derechos de negociación colectiva y de huelga, una particular manifestación de la libertad contractual. Es llamativo que estos derechos hayan sido consagrados expresa e independientemente del derecho de asociación y de la autonomía contractual, a pesar de la evidente relación existente entre ellos. Pero no debe perderse de vista que durante mucho tiempo

7 Pereira y SÁnchez (1992), 267. 
los derechos colectivos laborales no se entendían formar parte del contenido del derecho de asociación ni de la autonomía contractual. Incluso, se llegó a castigar penalmente las uniones de obreros y las paralizaciones de actividades laborales, y junto con ello los trabajadores no tenían la posibilidad de negociar en conjunto con su empleador.

Pero los movimientos sociales del siglo XIX condujeron a que los Estados reconocieran tales derechos en forma particularizada. Ello les ha dotado de una individualidad propia, que viene definida por dos elementos: 1 . dichos derechos son tres importantes instrumentos compensadores de la natural desigualdad entre trabajadores y empleadores; 2 . el objetivo último de estos derechos es la defensa de los intereses de los trabajadores. Es decir, su fin último es el logro de una mayor igualdad material entre las dos partes de la relación laboral. Y esa finalidad, propia del derecho del trabajo, se enmarca en la más amplia del constitucionalismo social, o sea, lograr igualdad material y mejorar las condiciones materiales de vida.

Además existe una razón formal para considerar a estos derechos como derechos sociales: están comprendidos en el Pacto Internacional de Derechos Económicos, Sociales y Culturales. Su reconocimiento es expreso en el caso de los derechos de sindicación y de huelga, y tácito respecto del derecho a la negociación colectiva.

Tampoco consiste en prestaciones el derecho a vivir en un medioambiente sano o descontaminado, consagrado en algunas constituciones (por ejemplo, Portugal, España, México, Chile, Argentina, Colombia). Se trata de un derecho que supone un deber de abstención por parte del Estado (no contaminar), como también la adopción por parte de éste de medidas destinadas a proteger el ambiente. Por ende, su carácter social deriva más bien de dos factores. El primero es que así es considerado por varios sistemas constitucionales. Y el segundo deriva del hecho de que está orientado a mejorar las condiciones de vida de toda la sociedad, lo que responde al modelo propio del constitucionalismo social, razón por la cual puede incluírsele como derecho social.

Por tanto, debe concluirse que lo determinante para saber si se está o no en presencia de un derecho social, no es la presencia o ausencia de prestaciones. Más aún, puede sostenerse que el elemento definidor de los derechos sociales no es único. Si bien uno de los factores determinantes de esta categoría de derechos es que muchos consisten en prestaciones, no puede olvidarse que hay otros que no consisten en prestaciones. Respecto de estos últimos, puede decirse que su carácter social deriva del hecho de que con su reconocimiento se persigue mejorar la situación social o la calidad de vida de un determinado grupo, como es el caso de los derechos colectivos laborales, o de toda la sociedad, como ocurre 
con el derecho a vivir en un medioambiente $\operatorname{sano}^{8}$. Todo ello, sin perjuicio de que, más allá de dichas consideraciones, existe un argumento adicional de carácter meramente normativo: en varias de las constituciones se incluye dentro de los derechos sociales a los derechos colectivos laborales y al derecho a vivir en un ambiente sano.

Pero su propia finalidad determina que la titularidad de estos derechos vaya unida a una cierta condición: los derechos sociales son derechos de trabajadores, de cesantes, de menesterosos, de enfermos, de jóvenes, de los sin casa. La excepción sería el derecho al medio ambiente descontaminado, cuya titularidad corresponde a toda la sociedad. Esta es una diferencia importante respecto de los derechos y libertades clásicos. Recuérdese que éstos emanan de la propia naturaleza humana, por lo cual todos somos titulares de ellos.

Por otra parte, el sujeto pasivo es por regla general el Estado, aunque respecto de determinados derechos también pueden serlo particulares, como ocurre con los derechos colectivos laborales y el derecho a un medio ambiente adecuado. En esto existe una similitud formal con los derechos clásicos, puesto que éstos también tienen al Estado como sujeto pasivo. Pero hay una diferencia de fondo entre ambas clases de derechos: por regla general el objeto de los derechos sociales exige actuación positiva de parte del Estado. La mayoría de estos derechos consisten en prestaciones de la más diversa índole ${ }^{9}$, salvo el caso de los derechos colectivos laborales y del derecho a un medio ambiente adecuado. Tanto éstos como los derechos y libertades liberales exigen de parte del Estado una actitud inversa: abstenerse de entorpecer su ejercicio.

\section{LOS DERECHOS SOCIALES CONSISTENTES EN PRESTACIONES ¿SON DERECHOS? ${ }^{10}$}

A estas alturas ya se ve que los derechos sociales distan mucho de ser un instituto coherente y bien definido. En su mayoría son prestaciones, pero algunos

\footnotetext{
${ }^{8} \mathrm{Al}$ respecto Ramos Tavares señala que los derechos sociales "tienen como destinatarios a todos los individuos, aunque pretenden, en especial, alcanzar a aquellos que necesitan de un amparo mayor", Ramos (2006), p. 730.

${ }^{9}$ En la sentencia rol $N^{\circ} 1710$, el Tribunal Constitucional reconoce el carácter prestacional de gran parte de estos derechos al señalar que "los principales derechos sociales que la Constitución asegura a todas las personas son configurados a partir de la posibilidad de acceder a una determinada prestación" (considerando 114").

${ }^{10}$ Perspectivas distintas de la sostenida aquí pueden verse, entre otros, en: CASCAJO (1988); MAYORGA (1990); Abramovich (2002); Bernal (2004); Arango (2005); Ramos (2006); Pisarello (2007); Palmer (2007); Jordán (2008); Carbonell (2008); De Paiva (2009); Nogueira (2009); Figueroa (2009). En general, en estos trabajos se sostiene no sólo que los derechos sociales son derechos, sino que también tienen una naturaleza similar a la de los clásicos o liberales.
} 
no lo son. Además, la forma en que se constitucionalizan no es la misma que la de los clásicos, y los constituyentes no han dotado de garantías jurisdiccionales a los que consisten en prestaciones. Esto último no es casual, sino que encuentra su razón en la distinta naturaleza de ambas categorías de derechos, cuyo análisis nos llevará a responder la pregunta de este epígrafe.

Una de sus cualidades esenciales de los derechos clásicos es su carácter absoluto $^{11}$, lo que no significa que no tengan límites. Ello porque, como destaca Ignacio de Otto, "cualquier derecho o libertad, fundamental o no, ampara aquello que ampara y nada más". Y así, por ejemplo, en el caso "de la prohibición de utilizar explosivos para hacer una obra de arte o en la de instalar un laboratorio peligroso en una vivienda, nos hallamos ante normas que no regulan supuestos de hecho pertenecientes al derecho fundamental, sino de otra naturaleza, aunque puedan guardar una ocasional relación con el derecho propiamente dicho. La sanción de un eventual incendio neroniano no es limitación del arte, sino sanción de un incendio" 12 .

En cambio, los derechos sociales que consisten en prestaciones no tienen ese carácter absoluto que presentan los clásicos. Si respecto de éstos el Estado no puede llevar a cabo una política que de manera permanente atente en su contra, no sucede lo mismo con los derechos sociales consistentes en prestaciones. Dado que la realización de éstos está entregada por regla general al Estado, ello determina que no tengan carácter absoluto, y que sus límites sean muy distintos que los de los derechos clásicos ${ }^{13}$. Estas características responden a varias razones:

A) La primera, y quizá la más importante, dice relación con los recursos económicos del Estado. Puesto que gran parte de los derechos sociales se materializan en prestaciones, el principal obligado a ellas, o sea el Estado, necesita contar con los recursos económicos indispensables para llevarlas a cabo. Pero el Estado, como cualquier agente económico, no puede sustraerse al problema básico sobre el que se estructura la ciencia económica: la escasez de los recursos. El factor económico determina que incluso el significado de cada uno de estos derechos sea diferente en los países subdesarrollados que en los desarrollados. Y aun entre éstos su situación también variará en relación a la situación económica de cada Estado ${ }^{14}$. Incluso la capacidad financiera de un mismo país "puede sufrir oscilaciones importantes

\footnotetext{
${ }^{11}$ Pereira (2006), pp. 257-262.

${ }^{12}$ De Отто (1988), p. 150, 146.

${ }^{13}$ Sobre las características de los derechos y libertades clásicos me remito a Pereira (2006), pp. 257-262.

${ }^{14}$ Mayorga (1990), p. 24.
} 
en plazos relativamente cortos" 15 . En definitiva, la aceptación y, sobre todo, el cumplimiento de los derechos sociales, dependen del grado de desarrollo de un país.

B) Por otro lado, el carácter no absoluto de los derechos sociales se ve reforzado por otras consideraciones. Así, por ejemplo, y a diferencia de los derechos liberales, por regla general los derechos sociales recogen más bien principios, programas o aspiraciones político-sociales, elevadas a nivel constitucional.

C) Asimismo, por tratarse de principios político-sociales o político-económicos, dependen en gran medida de las costumbres y opinión pública dominante. Piénsese, por ejemplo, en las "modas" o tendencias económicas del momento, las que ratifican que los derechos sociales están lejos de constituir un absoluto. Un buen ejemplo lo constituye la Unión Europea. Es un hecho que las políticas sociales han sido relegadas a un segundo plano, desplazadas por políticas económicas de ajuste, que apuntan a la igualación de las principales variables económicas de los países comunitarios. Todo ello ha supuesto claras restricciones al gasto público, lo que repercute desfavorablemente en las prestaciones y servicios a cargo del Estado.

D) No puede olvidarse tampoco que estos derechos no tienen un carácter absoluto para el constitucionalismo. De hecho, no son inherentes a la idea de Constitución, por lo que es perfectamente concebible una Constitución sin derechos sociales. Más aun, las Constituciones de mayor relevancia en el mundo, como la inglesa, la norteamericana e incluso la alemana, no cuentan con derechos sociales.

E) Pero, además, existe otra limitante intrínseca al concepto derechos sociales. Ya sabemos que estos derechos se caracterizan por el objetivo que persiguen: mejorar las condiciones materiales de vida y lograr una igualdad material entre los hombres, que es, a su vez, la fuente inspiradora de todo el constitucionalismo social. Dichas metas son antes que nada objetivos políticos, a los que el Derecho a lo más puede servir de instrumento para alcanzarlos. Y si bien los ideales que representan los derechos sociales pueden cumplir un papel importante como incentivo, no debe perderse de vista que, por ser ideales, no garantizan el éxito.

Sus propias limitaciones impiden atribuirle un contenido cierto a su formulación constitucional. Desde la óptica del art. 19 Nº 26 de la Constitución, puede decirse que, jurídicamente hablando, los derechos sociales de prestación carecen de un contenido esencial. Ello, porque la determinación de su contenido concreto corresponde al legislador, de acuerdo con los recursos disponibles. De ahí que los jueces puedan hacer poco o nada respecto de un derecho social prestacional no

${ }^{15}$ Contreras (1994), p. 112. 
desarrollado por aquél. La pura enunciación constitucional no hace posible su protección jurisdiccional ${ }^{16}$.

El sentido común y el realismo nos dicen que si bien esos ideales son una aspiración loable, su consecución resulta irrealizable. La Política no lo puede todo, de modo que no se puede esperar de ella milagros, ni en lo colectivo ni en lo personal. Y si la Política es limitada, con mayor razón lo es el Derecho, del que no se puede pretender obtener aquello que ni siquiera la Política es capaz de dar. Pedirle al Derecho lo que no le es propio resulta inadecuado, más aún cuando lo pedido es además utópico. Incurrir en tal error conlleva el grave riesgo de que el hombre pierda confianza en el Derecho.

Todo lo anterior lleva a dudar del supuesto carácter jurídico de los derechos sociales consistentes en prestaciones. Y es que si son derechos en sentido jurídico necesariamente deberían ser alegables ante los jueces, pues la mejor demostración de que algo es jurídico es su posibilidad de ser aplicado por éstos. Peces-Barba recuerda que una norma jurídica "necesita de los tribunales de justicia para que su titular pueda acudir en demanda de protección en caso de desconocimiento por un tercero". De ahí que si "un derecho fundamental no puede ser alegado, pretendiendo su protección, se puede decir que no existe" ${ }^{17}$. Y, precisamente, la naturaleza de los derechos sociales consistentes en prestaciones es no justiciable.

Debe ser por eso que Konrad Hesse se ha declarado en contra de la posible introducción en la Constitución alemana de preceptos programáticos sobre vivienda, empleo o medio ambiente. El destacado tratadista y ex miembro del Tribunal Constitucional germano sostiene que preceptos de este tipo suscitan expectativas: "Se leen en la Constitución y a continuación, lógicamente, hay que preguntarse: ¿Qué hay de las viviendas?, con el consiguiente efecto disfuncional si dichas expectativas no se ven cumplidas. La Constitución no debe prometer lo que no es capaz de cumplir". Y agrega que la Constitución "no es un programa político; al pretender convertirla en tal, se debilita el poder del legislador y se fuerza la capacidad de la Constitución"18.

La inclusión de derechos sociales de prestación en la Constitución, puede traducirse en una garantía de que el poder no los pueden derogar, lo que no es

\footnotetext{
${ }^{16}$ En palabras de Atria: "una norma que constitucionaliza un derecho social no contiene decisión política alguna que pueda ser entendida y aplicada por un juez en tanto juez". AtrIA (2004). A propósito del derecho a la protección de la salud, y en concreto, del deber correlativo que pesa sobre el Estado en orden a "garantizar la ejecución de las acciones de salud", la sentencia rol $N^{\circ} 1710$ reconoce que ello debe configurarse por la ley (considerando $123^{\circ}$ ).

${ }^{17}$ Peces-Barba (1980), p. 168.

${ }^{18}$ Cruz (1993), pp. 13-14.
} 
poco. Pero, de todas formas, su realización está sujeta a las condiciones económicas de cada momento. Por eso, su constitucionalización más que ser una garantía de la democracia puede, incluso, tornarse en contra de ésta, cuando la precariedad económica impida hacerlos efectivos en algún momento. Ello puede conducir a que los ciudadanos se sientan defraudados por la Constitución y pierdan confianza en ella, y probablemente también en el régimen democrático.

De ahí entonces que, desde el punto de vista jurídico, los derechos sociales consistentes en prestaciones no son derechos, pues no son justiciables. Loewenstein ya había advertido esto al señalar que los derechos sociales no "son derechos en sentido jurídico ya que no pueden ser exigidos judicialmente del Estado, antes de que no hayan sido institucionalizados por una acción estatal"19.

Y esto es así, incluso en el caso de que tales derechos contasen con algún mecanismo de garantía jurisdiccional, como sucede en la Constitución española con los derechos de los presos (artículo 25.2) y el derecho a la educación en lo relativo a prestaciones (apartados 4 y 9 del artículo 27), según se desprende del artículo 53. Es evidente que estos preceptos envuelven claros mandatos al poder político (Ejecutivo y Legislativo), pero cuesta imaginar que de ellos se deriven derechos correlativos, al menos en el sentido jurídico del término. La propia naturaleza de los preceptos hace difícil concebir la intervención judicial para el caso de incumplimiento de los mandatos. Y es que el otorgamiento de las prestaciones en que consisten la mayoría de los derechos sociales, está sujeta a una importante variable: la situación económica del Estado, y la forma en que se administran los recursos estatales. Ello determina las posibilidades de realización de dichas prestaciones, las que probablemente serán menores o ninguna en caso de crisis económica, o sea, precisamente cuando más falta pueden hacer.

Pero, en cualquier caso, la decisión acerca de cómo y en qué medida se otorgarán dichas prestaciones es una cuestión política, determinada por factores económicos. Y en este ámbito, desde la invención del viejo principio de separación de poderes, resulta claro que los jueces poco tienen que hacer. Por todo ello, resulta evidente que no puede hablarse de verdaderos derechos, en el sentido jurídico del término.

Tendrán un contenido cierto y determinado cuando el legislador se los dé. Sólo en ese momento se sabrá a ciencia cierta la magnitud de las prestaciones en que consisten, que estarán determinadas por las posibilidades económicas del momento. A lo anterior, se suma el hecho de que la obligación del legislador de desarrollar y dar contenido a estos derechos es meramente potestativa del sujeto obligado. Y como se verá al analizar brevemente la jurisprudencia española sobre

19 LoeWenstein (1976), p. 401. 
derechos sociales consistentes en prestaciones, parece que de poco sirve que éstos estén tutelados por garantías jurisdiccionales. Mientras no exista ley que determine su contenido concreto, los jueces poco o nada pueden hacer. Ello, porque en caso de intervenir invadirían competencias propias del poder político, que es el llamado a dar un contenido cierto y jurídicamente determinable al programa político en que consisten los derechos sociales de prestación.

En resumen, cuando los derechos sociales se traducen en prestaciones no pueden entenderse como facultades justiciables (derechos en sentido jurídico), sino como una aspiración o una meta social constitucionalizada. De hecho, esta es la posición que se desprende del art. $2^{\circ}$ apartados 1 y 3 del Pacto Internacionales de Derechos Sociales, Económicos y Culturales de 1966, según el cual

"1. Cada uno de los Estados Partes en el presente Pacto se compromete a adoptar medidas, tanto por separado como mediante la asistencia y la cooperación internacionales, especialmente económicas y técnicas, hasta el máximo de los recursos de que disponga, para lograr progresivamente, por todos los medios apropiados, inclusive en particular la adopción de medidas legislativas, la plena efectividad de los derechos aqui reconocidos.

3. Los paises en desarrollo, teniendo debidamente en cuenta los derechos humanos y su economía nacional, podrán determinar en qué medida garantizarán los derechos económicos reconocidos en el presente Pacto a personas que no sean nacionales suyos" (los destacados son mios).

Al respecto, el Comité de Derechos Económicos, Sociales y Culturales de las Naciones Unidas ha señalado que "el Pacto contempla una realización paulatina y tiene en cuenta las restricciones derivadas de la limitación de los recursos con que se cuenta". Por ello, las únicas obligaciones de carácter inmediato para los Estados parte son su compromiso de garantizar dichos derechos y asegurar que éstos "se ejercerán "sin discriminación..." ${ }^{20}$. Y agrega que "la principal obligación en lo que atañe a resultados que se refleja en el párrafo 1 del artículo $2^{\circ}$ es la de adoptar medidas "para lograr progresivamente... la plena efectividad de los derechos reconocidos [en el Pacto]". La expresión "progresiva efectividad" se usa con frecuencia para describir la intención de esta frase. El concepto de progresiva efectividad constituye un reconocimiento del hecho de que la plena efectividad de todos los derechos económicos, sociales y culturales en general no podrá lograrse en un breve período de tiempo. En este sentido, la obligación difiere de manera importante de la que figura en el artículo $2^{\circ}$ del Pacto Internacional de

\footnotetext{
${ }^{20}$ Observación general 3, de 14 de diciembre de 1990, "La índole de las obligaciones de los Estados Partes" (párrafo 1 del artículo $2^{\circ}$ del Pacto; Quinto período de sesiones, 1990), en http://www.acnur.org/biblioteca/ pdf/1452.pdf
} 
Derechos Civiles y Políticos e incorpora una obligación inmediata de respetar y garantizar todos los derechos pertinentes" (el destacado es mío).

No obstante, en un intento por dotar de un mínimo de eficacia al Pacto, el Comité señala también que, en su opinión, "corresponde a cada Estado Parte una obligación mínima de asegurar la satisfacción de, por lo menos, niveles esenciales de cada uno de los derechos. Así, por ejemplo, un Estado Parte en el que un número importante de individuos está privado de alimentos esenciales, de atención primaria de salud esencial, de abrigo y vivienda básicos o de las formas más básicas de enseñanza, prima facie no está cumpliendo sus obligaciones en virtud del Pacto”. Pero inmediatamente después matiza su posición al señalar que "toda evaluación en cuanto a si un Estado ha cumplido su obligación mínima debe tener en cuenta también las limitaciones de recursos que se aplican al país de que se trata”, lo que en todo caso deberá ser acreditado por el Estado (el destacado es mío).

\section{DERECHOS CLÁSICOS Y PRESTACIONES}

A la afirmación de que los derechos sociales consistentes en prestaciones tienen una naturaleza distinta que los clásicos o liberales, suele replicarse señalándose que no sólo aquellos derechos implican prestaciones. En concreto, se sostiene que varios derechos clásicos suponen también prestaciones y recursos económicos que permiten hacerlos efectivos, sin que por ello se ponga en duda su carácter de facultades justiciables. Tal es el caso, por ejemplo, del derecho al debido procedimiento jurídico y sus manifestaciones, del que en gran medida depende la eficacia de los demás derechos. Y es que el debido proceso conlleva la existencia no sólo de una estructura judicial, sino que también de las condiciones que permitan acceder a ella, y que ésta actúe con eficacia y rapidez ${ }^{21}$. Todo aquello tiene un marcado carácter prestacional, y supone medios destinados por el Estado para su realización. Así, las prestaciones no serían un elemento que por sí sólo sirva para establecer una diferencia de fondo entre los derechos sociales y los clásicos. Estos últimos también requieren de prestaciones para su real eficacia, y no por ello dejan de ser derechos en sentido jurídico.

Esta argumentación es en gran medida acertada, pero estimo que pierde de vista un factor de enorme relevancia, y que sin duda hace la diferencia entre ambas categorías de derechos. Me refiero al hecho de que el tránsito de una comunidad de mera subsistencia a una comunidad política basada en el constitucionalismo, implica algunos supuestos esenciales. Entre éstos se cuenta el reconocimiento de

\footnotetext{
${ }^{21}$ Sobre estos supuestos del debido proceso y su desarrollo doctrinario y jurisprudencial, en especial, en el sistema Interamericano de Derechos Humanos, ver CANÇADO (2008).
} 
ciertos ámbitos de inmunidad frente al poder político, que es precisamente en lo que consisten los derechos y libertades clásicos ${ }^{22}$. Ello conlleva que en la propia estructura de dicha comunidad política existan medios de resguardo de aquellas facultades, lo que sin duda involucra recursos materiales dispuestos para tal fin. Pero como precisamente la comunidad política se constituye para garantizar dichos derechos ${ }^{23}$, las prestaciones para lograr su eficacia son un supuesto de ella. De ahí, entonces, que la necesidad de contar con los medios necesarios para el aseguramiento de esos derechos y libertades, se reduce fundamentalmente a la existencia de mecanismos jurisdiccionales, y de una estructura administrativa puesta al servicio del resguardo de aquéllos.

Sin perjuicio de todo lo anterior, no cabe duda que incluso estas prestaciones que permiten dar eficacia a dichos derechos y libertades, están sujetas también a los recursos económicos con que cuente la comunidad política. Así las cosas, y tomando nuevamente el ejemplo del debido proceso, parece claro que los medios materiales indispensables para el funcionamiento de una estructura jurisdiccional dependerán de dicha variable, y que probablemente los estándares no serán iguales en un país del tercer mundo que en uno desarrollado. Y es que si bien el debido proceso supone la existencia de terceros imparciales y de procedimientos que observen ciertos principios indispensables, como el derecho a la defensa ${ }^{24}$, no cabe duda de que la mayor o menor eficacia de estos supuestos dependerá en parte de los medios materiales con que cuente el Estado.

\section{LOS DERECHOS SOCIALES DE PRESTACIÓN}

EN LA JURISPRUDENCIA ESPAÑOLA, NORTEAMERICANA Y CHILENA

\section{A) Un vistazo a los derechos sociales consistentes en prestaciones en la jurisprudencia española y norteamericana}

Se dijo antes que una limitante decisiva para la operatividad jurídica de los derechos sociales que consisten en prestaciones es la limitación de los recursos. Ello impide su justiciabilidad a partir de su mero reconocimiento constitucional. Así lo entendió el Tribunal Europeo de Derechos Humanos en el denominado "Caso

\footnotetext{
${ }^{22}$ Sobre el concepto de derechos y libertades, su naturaleza, características y relación con el constitucionalismo ver Pereira (2006), pp. 249-297.

${ }^{23}$ La Declaración de Independencia de los Estados Unidos proclamó no sólo como verdad autoevidente la existencia de derechos inalienables, entre los que se cuentan la vida, la libertad y la búsqueda de la felicidad, sino que además "para garantizar estos derechos se instituyen entre los hombres los gobiernos".

${ }^{24}$ Derecho a ser oído, derecho a la bilateralidad de la audiencia y derecho a rendir pruebas.
} 
Airey", de 9 de octubre de $19799^{25}$. En él, el Tribunal señaló que "la progresiva realización de los derechos sociales y económicos depende de la situación de cada Estado, y sobre todo de su situación económica”.

La misma línea jurisprudencial, aunque formulada quizá más contundentemente, fue adoptada por el Tribunal Constitucional español, en su sentencia 77/1985, de 27 de junio. En ésta señaló que "el legislador se encuentra ante la necesidad de conjugar, no sólo diversos valores y mandatos con la insoslayable limitación de los recursos disponibles" (fundamento jurídico 11). Esta idea fue reiterada en la sentencia 134/1987, de 21 de julio, al señalar que el Estado debe "administrar medios económicos limitados para un gran número de necesidades sociales". Podría decirse que esta jurisprudencia es una especie de ratificación del viejo aforismo que señala que "al imposible nadie está obligado". Y a propósito de los derechos sociales de prestación, menos obligado puede estar el Estado a satisfacerlos cuando la economía esté en crisis.

Ejemplos concretos de lo recién señalado se encuentran en cuatro decisiones del propio Tribunal Constitucional español, a propósito del derecho de los presos a un puesto de trabajo y a los beneficios de la seguridad social, reconocido en el art. 25.2 de la Constitución española. Este derecho presenta la particularidad de que goza de la garantía jurisdiccional del recurso de amparo de que conoce el mismo Tribunal, es decir, el constituyente lo hizo justiciable. No obstante, las cuatro decisiones que se verán a continuación demuestran que de poco sirve garantizar jurisdiccionalmente derechos sociales consistentes en prestaciones consagrados en una Constitución.

El primer ejemplo de lo ya dicho está contenido en el auto número 256/1988, de 29 de febrero. El caso sobre el que recayó esta primera decisión, tiene su origen en la solicitud dirigida por un preso al centro penitenciario en que estaba recluido, mediante la cual pedía que se le proporcionase un puesto de trabajo y los beneficios de la seguridad social reconocidos en aquel artículo. Denegada su solicitud por la Administración penitenciaria y por la justicia contencioso administrativa, interpuso recurso de amparo ante el Tribunal Constitucional.

En el fundamento único del auto, el Tribunal Constitucional declaró inadmisible el recurso de amparo. A juicio del Tribunal el derecho a un trabajo remunerado y a los beneficios de la seguridad social son "derechos de aplicación progresiva". Más aún, su "efectividad se encuentra en función de los medios que la Administración Penitenciaria tenga en cada momento, no pudiendo, por tanto, ser exigidos en su totalidad de forma inmediata, siempre que realmente

\footnotetext{
${ }^{25}$ El caso puede consultarse en la página web de la Corte Europea de Derechos Humanos http://cmiskp. echr.coe.int/tkp197/portal.asp?sessionId=40474904\&skin=hudoc-en\&action=request
} 
exista imposibilidad material de satisfacerlos". Por esas consideraciones, el derecho a un trabajo remunerado y a los beneficios de la seguridad social, sólo tiene relevancia constitucional "si se acredita que el Centro Penitenciario en que se cumple la condena existe puesto de trabajo, a cuya adjudicación se tenga derecho dentro del orden de prelación citado y, en tal supuesto, la autoridad judicial con competencia para ello incumplirá su obligación de amparar el citado derecho en el caso de que no adopte las medidas adecuadas para compeler a la Administración a que lo satisfaga”.

El segundo ejemplo es el del auto 95/1989, de 20 de febrero, en el que el Tribunal Constitucional español reiteró la jurisprudencia sentada por el anterior. Este auto deja entrever claramente que no es posible recurrir en amparo, para solicitar que la administración cree un puesto de trabajo inexistente. Al igual que en el auto precedente, su único fundamento jurídico señala que tanto el derecho como los beneficios "alcanzan relevancia constitucional únicamente si se acredita que en el centro penitenciario en el que se cumpla la condena existe puesto de trabajo a cuya adjudicación se tenga derecho dentro del orden de prelación establecido -el cual no podrá ser arbitrario o discriminatorio-, pese a lo cual la autoridad judicial no adopta las medidas adecuadas para compeler a la Administración a que lo satisfaga". Es decir, sólo puede hablarse de un verdadero derecho del preso a nivel infraconstitucional, pero no desde la Constitución.

La doctrina de ambos autos es recogida posteriormente en lo que constituye nuestro tercer ejemplo, la sentencia del Tribunal Constitucional 172/1989, de 19 de octubre. $\mathrm{Al}$ igual que en los amparos que originaron los autos anteriores, en este caso un recluso solicitó al centro penitenciario le fuese reconocido su derecho al trabajo y a los beneficios de la seguridad social. Al no haberse satisfecho su petición ni en sede administrativa ni en el contencioso administrativo, interpuso recurso de amparo ante el Tribunal Constitucional, fundado en la supuesta infracción del artículo 25.2 de la Constitución. Si bien en la sentencia el Tribunal Constitucional comienza su razonamiento reiterando "la indudable eficacia directa e inmediata de la Constitución” (fundamento jurídico 2), a continuación introduce una importante matización, que lleva a relativizar esa afirmación. A su juicio, es preciso tener en consideración la naturaleza del derecho del art. 25.2, que implica prestaciones, por lo que se trata de "un derecho de aplicación progresiva, cuya efectividad se encuentra condicionada a los medios de que disponga la Administración en cada momento, no pudiendo pretenderse, conforme a su naturaleza, su total exigencia de forma inmediata" (fundamento jurídico 3).

Nuestro cuarto ejemplo es la sentencia del Tribunal Constitucional español 17/1993, de 18 de enero. De nuevo los hechos son similares a los que dieron 
origen a la jurisprudencia anterior, y conducen a que un interno interponga recurso de amparo fundado en la supuesta infracción del artículo 25.2. En esta ocasión el Tribunal comenzó sus razonamientos de manera lapidaria, al señalar que el derecho cuya tutela se solicitaba "no supone su configuración como un verdadero derecho subjetivo perfecto del interno frente a la Administración..." (fundamento jurídico 2).

Todo lo anterior nos lleva a afirmar que la consagración de derechos sociales consistentes en prestaciones en una Constitución sólo genera un deber político: implementarlos y darle contenido. Y este deber se relaciona con la manera en que el poder político administra el Estado. $\mathrm{Y}$ en ese ámbito los tribunales poco tienen que hacer. Como recuerda Enrique Alonso García, la Corte Suprema de Estados Unidos de Norteamérica ha tenido oportunidad de pronunciarse sobre la competencia de los tribunales para determinar cómo se debe administrar económicamente el país. Tal pronunciamiento se ha presentado a propósito de la discusión sobre agregar o no a los derechos tradicionales nuevos derechos de que implican prestaciones. Se concluyó que no debía agregarse esta clase de derechos, ya que sería contrario al principio de soberanía parlamentaria en la ordenación del gasto público: el eventual reconocimiento de tales derechos conllevaría un aumento de tal gasto. La Corte ha declarado que "el reconocimiento y administración de prestaciones sociales no es una función judicial, sino legislativa o administrativa por su propia naturaleza" ${ }^{26}$. La Corte sólo entra a enjuiciar si una determinada política social se ajusta o no a los parámetros propios del principio de igualdad ante la ley ${ }^{27} \mathrm{y}$ del debido procedimiento jurídico ${ }^{28}$, pero no respecto a si se debe o no implementar una política social, y cómo debe hacerse.

El Tribunal Constitucional español ha emitido un pronunciamiento similar a la posición de la Corte Suprema norteamericana en la sentencia 90/1989, de 11 de mayo. En este fallo se resolvió un recurso de amparo interpuesto por un campesino contra la resolución administrativa que le negó lugar a una solicitud de subsidio de desempleo. Dicha resolución se fundaba en que el subsidio solicitado estaba establecido sólo en favor de campesinos desempleados de las Comunidades Autónomas de Andalucía y Extremadura, y el solicitante no vivía en ninguna de éstas, sino en Murcia. El Tribunal sostuvo que es competencia del gobierno establecer el alcance y ámbito de aplicación de subsidios de desempleo, en función de los

\footnotetext{
${ }^{26}$ Alonso García (1982), p. 163.

${ }^{27}$ Es lo que ha hecho más recientemente en Zelman v. Simmons, 536 U.S. 639 (2002), o en Parents Involved in Community Schools v. Seattle School District $N^{\circ} 1$ et al 551 US (2007), en que el parámetro de control ha sido el principio de igualdad.

${ }^{28}$ Por ejemplo, Fullilove v. Klutznick 448 U.S. 448 (1980).
} 
fondos disponibles y la magnitud del problema del paro, "y no puede el Tribunal Constitucional sustituir a ese órgano del Estado en tal función".

\section{B) Derechos sociales de prestación en la jurisprudencia chilena}

En nuestro país, tanto la Corte Suprema como el Tribunal Constitucional han tenido la oportunidad de pronunciarse respecto del valor y eficacia de los derechos sociales de prestación. La primera, lo ha hecho al conocer como tribunal de segunda instancia en varios recursos de protección (art. 20 de la Constitución). Por su parte, el Tribunal Constitucional ha entregado su posición en cuatro cuestiones de inaplicabilidad y en una declaración de inconstitucionalidad (art. $93 \mathrm{~N}^{\circ} 6$ y $\mathrm{N}^{\circ} 7$ de la Constitución).

\section{En la jurisprudencia de la Corte Suprema}

En nuestro país, la jurisprudencia de la Corte Suprema parece haberse encaminado en la misma línea que la de su símil norteamericana y del Tribunal Constitucional español. Si bien, en general, los derechos sociales que consagra nuestra Constitución no son justiciables ${ }^{29}$, son varios los casos en que se ha procurado soslayar dicha característica mediante la vinculación de los hechos a derechos clásicos. Es lo que sucede cuando se vincula, por ejemplo, el derecho a la protección de la salud con el derecho a la vida. Sin embargo, los resultados de esta estrategia no han sido favorables para quienes la han intentado. Así, la jurisprudencia ha entendido que el derecho a la vida no puede dar cobertura a la salud, porque aquél dice relación con la protección frente a los ataques a la vida por la acción de terceros, y no por enfermedades. Y a su vez, en lo que resulta más sintomático respecto de la naturaleza de los derechos sociales, la jurisprudencia ha señalado que la protección de la salud está limitada por los recursos económicos con que cuente el Estado.

En Gallardo Soto con Servicio de Salud Metropolitano Oriente ${ }^{30}$, la Corte Suprema tuvo que pronunciarse respecto de la imposibilidad de brindar de inmediato un tratamiento de diálisis por parte de los organismos de salud. En la sentencia sostuvo que "no puede calificarse de arbitraria la negativa de que se reclama, dado

\footnotetext{
${ }^{29}$ La excepción la constituyen el derecho a vivir en un ambiente libre de contaminación; el derecho a la protección de la salud en lo relativo a la facultad de elegir entre el sistema público y el privado de salud, y el derecho de sindicación, que sí están garantizados por el recurso de protección.
}

${ }^{30}$ Corte Suprema, Gallardo Soto con Servicio de Salud Metropolitano Oriente (1988). 
que ella se funda en que ese Servicio no dispone de los medios que la ley ${ }^{31}$ prevé para la atención que se solicita, y este hecho priva a la negación de la condición de abusiva o carente de justificación”. Y agregó que dicha conducta tampoco era ilegal "toda vez que es la propia ley la que condiciona el otorgamiento de las prestaciones que otorga al disponer que los beneficiarios tendrán derecho a las acciones de salud previstas en ella en las condiciones que esa misma ley establece y que las prestaciones se concederán con los recursos profesionales, técnicos y administrativos de que dispongan los establecimientos" (considerando 10).

A su vez, en Sepúlveda Parías con Subdirector del Hospital Barros Luco-Trudeau $^{32}$, la Corte Suprema debió pronunciarse también acerca de la no prestación de un tratamiento de diálisis por falta de medios materiales. En concreto señaló que "en el caso de autos, y de acuerdo al mérito del proceso, existe insuficiencia de elementos para practicar tratamientos de diálisis, lo que evidentemente tendrá influencia en la salud del enfermo" (considerando 7). Y a efectos de demostrar que este hecho escapa a la competencia de los jueces señaló dos argumentos. En primer lugar sostuvo que al no poder darse tratamiento "a todos los pacientes, le corresponderá al profesional médico la determinación entre las alternativas que conduzcan a saber quién y cuándo se atiende" (considerando 7). Y en segundo lugar, hizo presente que si se hiciera lugar al recurso "se le daría una irregular preferencia al enfermo que interpone un recurso de protección, si no se le atiende al requerir un servicio como el que es aquí analizado, por sobre otros que adoleciendo del mismo mal, no se han adelantado a llevar a los tribunales de justicia por medio de la protección al reclamo contra el Servicio que debe dar esa atención médica, el que se sujeta a normas propias o "listas de espera" para esa atención formada a base de edad, naturaleza de la enfermedad u otras razones de índole estrictamente médico y particular o propia del respectivo enfermo que requiere de la atención de que se trata" (considerando 8).

Por su parte, en Colegio Médico de Chile AG (Consejo Regional Valparaíso) con Secretario Regional Ministerial de Salud de Valparaíso y Director del Servicio de Salud Viña del Mar-Quillota ${ }^{33}$, la Corte Suprema se pronunció respecto de una serie de retrasos en alrededor de tres mil operaciones quirúrgicas. Haciendo suyo el voto de minoría de la Corte de Apelaciones de Valparaíso, sostuvo que "del mérito de los informes de los recurridos se desprende que existe un criterio

\footnotetext{
${ }^{31}$ Ley No 18.469.

${ }^{32}$ Corte Suprema, Sepúlveda Parias con Subdirector del Hospital Barros Luco-Trudeau (1987). En un sentido similar Corte Suprema, Gracia Zúñiga con Servicio de Salud Metropolitano Norte (1987).

${ }^{33}$ Corte Suprema, Colegio Médico de Chile AG (Consejo Regional Valparaíso) con Secretario Regional Ministerial de Salud de Valparaíso y Director del Servicio de Salud Viña del Mar-Quillota (2001).
} 
para la atención de operaciones de los pacientes que se materializa en una política de Bases y Estrategias de Salud Regional, la que se encuentra bajo supervisión y que en dicho caso se ve limitada por la disponibilidad presupuestaria, lo que no depende de los recurridos", y que "si bien existe lo que se denomina "operaciones electivas" debe considerarse que el Fondo Nacional de Salud no financia el costo total de dichas operaciones, lo que conlleva deterioro económico para el Servicio de Salud, y ello deja en evidencia limitaciones de presupuestos que no son de su responsabilidad, no habiéndose acreditado que los procedimientos en comento y contra los cuales se reclama sean arbitrarios o ilegales".

Asimismo, en Rojas Vera y otros con Servicio de Salud Metropolitano Oriente y Ministerio de Salud ${ }^{34}$, la Corte Suprema reitera la idea de que la satisfacción de prestaciones de salud está en directa relación con los recursos económicos disponibles para tal efecto. En concreto señaló que de acuerdo a la ley ${ }^{35}$ dichas prestaciones se relacionan con políticas de salud que "deben ser definidas y aplicadas por las autoridades pertinentes del Ministerio indicado, que constituyen el personal idóneo para la fijación de las normas de acceso a las prestaciones que, como en el caso de autos, se pretenden, habida cuenta que en su otorgamiento han de tenerse en cuenta variados parámetros, entre otros, como resulta evidente, el relativo a los costos que ellos involucren y los fondos de que se dispongan para ello" (considerando 3). Precisando aún más su posición, agregó expresamente que "atañe a las autoridades de salud llevar a la práctica las políticas de salud diseñadas e implementadas por la Administración del Estado acorde con los medios de que disponga para ellos y con otros parámetros que no cabe dilucidar por esta vía" (considerando 6). Todo ello, sin perjuicio de que "la protección estatal a la salud se encuentra contemplada como garantía constitucional en el artículo $19 \mathrm{~N}^{\circ} 9$ y de éste, lo único incluido en el recurso de protección es el inciso final, referido a que cada persona tendrá el derecho a elegir el sistema de salud al que desee acogerse, sea éste estatal o privado, lo que no es el caso de autos" (considerando 7).

En Ossa Aránguiz con Ministerio de Salud, Servicio de Salud del Maule y Servicio de Salud Metropolitano Norte ${ }^{36}$, se cierra de manera expresa y definitiva la posibilidad de interpretar el derecho a la vida y a la integridad física y síquica como facultades que conlleven prestaciones justiciables. Al respecto el fallo señala

\footnotetext{
${ }^{34}$ Corte Suprema, Rojas Vera y otros con Servicio de Salud Metropolitano Oriente y Ministerio de Salud (2001).

${ }^{35}$ Artículo 11 de la Ley No 18.469 que "Regula el ejercicio del Derecho Constitucional a la protección de la salud y crea un Régimen de Prestación de Salud".

${ }^{36}$ Corte Suprema, Ossa Aránguiz con Ministerio de Salud, Servicio de Salud del Maule y Servicio de Salud Metropolitano Norte (2002).
} 
que "la garantía del derecho a la vida e integridad física o síquica, que se denuncia como vulnerado, apunta a proteger sólo las conductas que ponen en riesgo y en peligro la vida humana, en este caso, el supuesto peligro de estos pacientes proviene de la enfermedad que ellos padecen y en ningún caso de la autoridad sanitaria, que no ha tenido ninguna relación con el origen de la enfermedad, por consiguiente, estos enfermos al acudir a los distintos Servicios de Salud a solicitar ayuda médica, ya tienen su salud amenazada por la enfermedad que adolecen, la que es causada por un gen de la cual los recurridos de autos, no tienen ninguna responsabilidad, ni participación" (considerando 8).

Un criterio similar ha sido recientemente reiterado en Marcell Chacón con Servicio de Salud Metropolitano Occidente ${ }^{37}$. La Corte Suprema volvió a sostener que cuando la amenaza a la vida de una persona deriva de una patología, no se cumple el requisito de que aquélla sea imputable a alguien, supuesto en el que descansa el recurso de protección. Por ende, no puede basarse la acción en una presunta lesión al derecho a la vida, cuando en verdad lo que se pretende es obtener una prestación de salud, cuestión que queda fuera de la cobertura de dicho recurso, ya que no ampara los aspectos consistentes en prestaciones del derecho a la protección de la salud del art. 19 No 9.

2. ¿Pueden los jueces hacer más por los derechos sociales consistentes en prestaciones? Los derechos a la protección de la saludy a la seguridad social en la jurisprudencia del Tribunal Constitucional

En las sentencias roles $\mathrm{No}^{\circ}$. 976, 1218, 1273, 1287 y 1770, el Tribunal Constitucional ha tenido la posibilidad de entregar su visión respecto del valor y eficacia de los derechos sociales en general, y en particular, de los que consisten en prestaciones. Más concretamente, el Tribunal se ha pronunciado respecto del valor y eficacia de los arts. 19 No 9 y 18 de la Constitución, que reconocen el derecho a la protección de la salud y el derecho a la seguridad social, respectivamente. De acuerdo al primer precepto, el Estado debe proteger "el libre e igualitario acceso a las acciones de promoción, protección y recuperación de la salud y de rehabilitación del individuo", y tiene a su cargo "la coordinación y control de las acciones relacionadas con la salud", y debe "garantizar la ejecución de las acciones de salud" (incisos $2^{\circ}, 3^{\circ}$ y $4^{\circ}$ ). Pero, además, la Constitución reconoce "el derecho a elegir el sistema de salud al que desee acogerse, sea éste estatal o privado" (inciso $5^{\circ}$ ). Por su parte, el numeral 18 del art. 19, después de reconocer el derecho a la seguridad social, dispone que la "acción del Estado estará dirigida a garantizar el acceso de

${ }^{37}$ Corte Suprema, Marcell Chacón con Servicio de Salud Metropolitano Occidente (2009). 
todos los habitantes al goce de prestaciones básicas uniformes, sea que se otorguen a través de instituciones públicas o privadas". Asimismo, faculta al legislador para que establezca cotizaciones obligatorias, e impone al Estado el deber de supervigilar "el adecuado ejercicio del derecho a la seguridad social" (incisos $3^{\circ}$ y $4^{\circ}$ ).

En virtud de lo anterior, en nuestro país las personas pueden optar por recibir servicios de salud públicos o privados. La regulación de estos deberes impuestos al Estado, y del derecho recién mencionado, descansa en la actualidad de manera particular en el D.F.L. No 1 , de 2005, que fijó el texto refundido, coordinado y sistematizado del Decreto Ley No 2.763, de 1979 y de las Leyes Nos. 18.933 y 18.469. Es en el ámbito de este marco normativo que se desarrolla la actividad de las denominadas Instituciones de Salud Previsional (Isapres), empresas privadas que otorgan prestaciones de salud con cargo a las cotizaciones de las personas que quieran contratar con ellas, en virtud del derecho constitucional del inciso $5^{\circ} \mathrm{del}$ art. 19 No 9 de la Constitución.

La relación entre las personas y las Isapres es de carácter contractual, según se desprende del art. 184 del D.F.L. No 1 de 2006, y la libertad de las partes está regulada y limitada por una serie de condiciones y prohibiciones. Entre las condiciones está la posibilidad de las Isapres de revisar los precios de los planes de salud que ofrecen. Para tal efecto deben aplicar a los precios base "el o los factores que correspondan a cada beneficiario, de acuerdo a la respectiva tabla de factores" (art. 199 inc. $1^{\circ}$ ). La estructura de la tabla de factores es fijada por la Superintendencia de Salud mediante acto administrativo, en el que debe considerar como parámetros el sexo y condición de cotizante o carga, y rangos de edad. Estos últimos los fija la propia ley (art. 199), y las Isapres tienen libertad "para determinar los factores de cada tabla que empleen" (art. 199).

Este marco regulatorio permitió que cuatro Isapres ajustaran los precios de los planes de salud contratados con otras tantas personas. Tres de éstas interpusieron recursos de protección reclamando de la tabla de actores aplicada y del consiguiente aumento en sus planes (casos resueltos en los roles $\mathrm{N}^{\circ}$ s. 976, $1273 \mathrm{y}$ 1287). La cuarta reclamó de la tabla y del aumento ante el Intendente de Fondos y Seguros de Salud, quien actúa como árbitro arbitrador (el caso rol No 1218). Estando pendiente estas cuatro gestiones se interpusieron otras tantas cuestiones de inaplicabilidad, que más tarde motivan la declaración de inconstitucionalidad de los números 1, 2, 3 y 4 del inciso tercero del artículo 38 ter de la Ley No 18.933 (sentencia rol $\mathrm{N}^{\circ} 1710^{38}$ ). Estas cinco sentencias conforman la actual doctrina de

\footnotetext{
${ }^{38}$ En el voto de mayoría de este fallo se señala que quienes lo suscriben llegaron a la "convicción en cuanto a que los números 1, 2, 3 y 4 del inciso tercero del artículo 38 ter de la Ley No $18.933 \ldots$, son incompatibles con el derecho a la igualdad ante la ley, especialmente entre hombres y mujeres, y lesionan, asimismo, el de-
} 
mayoría del Tribunal Constitucional respecto de los derechos sociales consistentes en prestaciones.

\section{a) La opinión de mayoría}

A pesar de la clara posición adoptada por la Corte Suprema, los fallos del Tribunal Constitucional en las causas roles Nos. 976, 1218, 1273, 1287 y 1710, parecen poner en tela de juicio la línea jurisprudencial esbozada precedentemente. En todos estos casos el Tribunal conoció de inaplicabilidades en contra del artículo 38 ter de la Ley No 18.933 (roles $\mathrm{No}_{\text {s. }} 976$ y 1218) y del artículo 199 del Decreto con Fuerza de Ley (Ministerio de Salud) No 1, de 2005, que fija el texto refundido, coordinado y sistematizado del D.L. No 2.763, de 1979, y de las leyes $\mathrm{No}^{\circ} .18 .933$ y 18.469 (rol No 1287), por supuesta infracción a los derechos de los numerales 2, 9 y 24 del artículo 19 de la Constitución. La sentencia rol No 976 acogió la inaplicabilidad, en consideración a que la aplicación del art. 38 ter de la Ley No 18.933 vulneraría el derecho a la salud del art. $19 \mathrm{~N}^{\circ} 9$ de la Constitución. A su vez, las sentencias roles $\mathrm{No}^{\circ}$. 1218 y 1287, acogieron las respectivas inaplicabilidades en atención a que la aplicación del ya mencionado art. 38 ter, y el artículo 199 del Decreto con Fuerza de Ley (Ministerio de Salud) No 1 , de 2006, infringirían los artículos $1^{\circ}, 5^{\circ}, 6^{\circ}, 19, \mathrm{No}^{\circ} .2,9,18,24$ y 26 de la Constitución. Finalmente, la sentencia rol No 1710 consideró que los numerales 1, 2, 3 y 4 del inciso tercero del artículo 38 ter de la Ley No 18.933 infringían la igualdad ante la ley, el derecho a la protección de la salud y el derecho a la seguridad social, además del principio de reserva legal. Los argumentos de la mayoría pueden resumirse en los siguientes puntos:

i. Los derechos sociales no son meras expectativas, sino que auténticos derechos. Los votos de mayoría de estas sentencias señalan que los derechos sociales son efectivamente derechos " $y$ no simples declamaciones o meras expectativas, cuya materialización efectiva quede suspendida hasta que las disponibilidades presupuestarias del Estado puedan llevarlos a la práctica" (sentencias roles $\mathrm{No}_{\text {s. }}$ 976, considerando $26^{\circ} ; 1218$, considerando $20^{\circ}$, y 1287 , considerando $20^{\circ}$, respecti-

recho a la protección de la salud y el derecho a la seguridad social, en el sentido que todos ellos se encuentran reconocidos y asegurados en nuestra Carta Fundamental" (considerando $144^{\circ}$ ). No obstante, es importante precisar que el único argumento que permitió la declaración de inconstitucionalidad es la vulneración por parte del legislador del principio de reserva legal. Ello, porque los 4/5 exigidos por la Constitución para proceder a la derogación de la norma, se lograron gracias a que el Ministro Sr. Bertelsen suscribió precisamente esa única infracción, y no la de la igualdad ante la ley, el derecho a la protección de la salud y el derecho a la seguridad social. Ver considerandos 149-151, y prevención del referido Ministro. Los votos de minoría son los de los ministros Peña, Fernández Fredes y Vodanovic y Navarro. 
vamente). Sostuvo, asimismo, que el derecho a la protección de la salud "se halla sustancialmente ligado a otros atributos esenciales asegurados en nuestro Código Político, v. gr., el derecho a la vida y a la integridad tanto física como psíquica, todos los cuales deben ser tutelados y promovidos para infundir al ordenamiento la legitimidad ya aludida" (considerandos $32^{\circ}$ de las sentencias roles $\mathrm{No}_{\text {s. }}$ 976, $1218,1287)$. En tal sentido, las sentencias roles $\mathrm{No}_{\text {s. }} 1273$ y 1710 señalan que los derechos "no pueden ser considerados de manera aislada o independiente unos de otros. Al contrario, ellos se manifiestan de manera integrada, constituyendo un entramado de normas y principios cuyo alcance no puede apreciarse correctamente sin considerar una visión de conjunto que los incluya a todos ellos y que, también, incorpore su relación con otras disposiciones y valores constitucionales" (considerandos $47^{\circ}$ y $88^{\circ}$, respectivamente). Todo ello lleva al Tribunal Constitucional a considerar derechamente a los derechos sociales como derechos fundamentales (sentencia rol No 1710 , considerando $\left.94^{\circ}\right)^{39}$.

ii. El efecto horizontal de los derechos y el principio de subsidiariedad imponen a los particulares el deber de dar eficacia a los derechos sociales. El Tribunal Constitucional señaló también que como la Constitución es un sistema orgánico, coherente y armónico de valores, principios y normas, ello excluye toda interpretación que anule o prive de eficacia a alguno de sus preceptos. Esto lleva a la mayoría a darle una nueva al principio de subsidiariedad, al señalar que "no sólo los órganos del Estado deben respetar y promover los derechos consustanciales a la dignidad de la persona humana, sino que esa obligación recae también en los particulares, aunque sea subsidiariamente, puesto que el Código Supremo asegura la intangibilidad de tales atributos en toda circunstancia, cualesquiera sean los sujetos que se hallen en la necesidad de infundir vigencia efectiva a lo proclamado en sus preceptos" (sentencias roles $\mathrm{No}^{\circ}$. 976 , considerando $34^{\circ} ; 1218$, considerando $35^{\circ}$, y 1287 , considerando $35^{\circ}$, respectivamente).

En otros términos, el Tribunal entendió que los derechos sociales también resultan exigibles respecto de particulares, por aplicación del principio de efec-

\footnotetext{
${ }^{39}$ Es importante considerar que la expresión "derechos fundamentales" tiene su origen en Alemania (Grundrechte), e implica la idea de que los derechos son "el fundamento de todo el sistema jurídico y valorativo, un sistema de juicios de valor y elecciones éticas, siendo la propia Constitución..., 'un conjunto de valores positivizado’ que deben permearlo todo”. Pereira (2006), 251. Pero suele olvidarse que la visión alemana de la Constitución y los derechos no es la única, ni es la que se corresponde con los orígenes y sentido del Derecho Constitucional y de la Constitución. Como apunta el propio Pereira, en las tradiciones constitucionales inglesa, norteamericana y francesa, los derechos han sido vistos de distinta manera "("los derechos de nacimiento de un inglés", "libertades", "libertades cívicas", "libertades públicas") no como fundamento de la comunidad política ni del sistema jurídico, ni como conjunto de valores, sino como un freno o limitación destinada a protegernos de las interferencias del Estado". Ibíd.
} 
to horizontal de los derechos. Pero junto a ello, se deriva la obligación de los particulares de dar eficacia a tales derechos en subsidio del Estado. Tal sería el caso de las Isapres, como consecuencia de la aplicación a su respecto del art. 19 $\mathrm{No}$ s. 9 (en lo relativo al derecho a elegir entre el sistema público o privado de salud) y 26 (sentencias roles $\mathrm{No}^{\circ}$ s. 976 , considerandos $36^{\circ}, 37^{\circ}, 38^{\circ}$ y $42^{\circ} ; 1218$, considerandos $37^{\circ}, 38^{\circ}, 39^{\circ}$ y $43^{\circ}$, y 1287 , considerandos $37^{\circ}, 38^{\circ}, 39^{\circ}$ y $43^{\circ}$, respectivamente).

iii. La posibilidad de establecer diferencias de precios en los contratos de salud en razón de edad y de sexo constituye una discriminación arbitraria e irrazonable, y es una infracción a la igualdad efectiva. Como consecuencia de lo anterior, la posición de mayoría del Tribunal Constitucional entiende que la aplicación de las tablas de factores efectuada por las Isapres para modificar el precio del contrato de salud, constituye una "discriminación infundada o distinción carente de justificación razonable y, en esa medida, arbitraria". Ello porque, a su juicio, si bien la referida tabla encuentra fundamento en la ley, "se torna evidente que tal disposición lesiona la esencia de la igualdad entre las partes asegurada por el artículo 19, № 2, de la Constitución" (sentencia rol No 976, considerando 62).

La posición de mayoría del fallo rol $\mathrm{N}^{\circ} 1273$ precisa que no es acorde a la Constitución el criterio del art. 38 ter de la Ley $\mathrm{N}^{\circ} 18.933$, en cuanto permite fijar los precios de los contratos de salud en consideración de la edad y del sexo. Para tal efecto, el Tribunal Constitucional hace suya una doctrina de su símil alemán, según la cual "es necesario distinguir conceptualmente entre 'igualdades esenciales' y 'desigualdades esenciales'. Así, estamos en presencia de una igualdad esencial cuando 'personas, grupos de personas o situaciones, sobre la base de un punto de partida (tertium comparationis), son comparables"' (sentencia rol $\mathrm{N}^{\circ} 1273$, considerando $60^{\circ}$ ).

Por tal razón, se lesiona "la igualdad ante la ley cuando un grupo de destinatarios de la norma, comparados con otro grupo de destinatarios de la norma, son tratados de manera distinta, a pesar de que entre ambos grupos no media ninguna diferencia de tal entidad o importancia que pudiera justificar un tratamiento desigual. Para poder dimensionar tales situaciones, esta fórmula requiere expresamente una ponderación en el sentido de examen de proporcionalidad, especialmente respecto de una diferencia de trato de gran intensidad, para lo cual se requiere que aquélla persiga un fin legítimo, que esa búsqueda sea necesaria y que presente una razonable relación con el valor del fin propuesto" (sentencia rol $\mathrm{N}^{\circ} 1273$, considerando 60).

Pero el Tribunal Constitucional precisa que la igualdad infringida por la ley es la "igualdad efectiva, que se encuentra establecido en el inicio del segundo inciso 
del número $9{ }^{\circ}$ del artículo 19 de la Constitución: 'El Estado protege el libre e igualitario acceso a las acciones de promoción, protección y recuperación de la salud y de rehabilitación del individuo'. Como la expresión 'acciones' se repite en todo el resto del precepto, debe entenderse que el acceso igualitario abarca a todas ellas, sean las que se presten a través de instituciones públicas o privadas" (considerando 64). Todo ello lleva al voto de mayoría a sostener que "la diferenciación por sexo y edad que permite el artículo 38 ter de la Ley $\mathrm{N}^{\circ} 18.933$, impugnado en estos autos, establece un trato desigual para igualdades esenciales, como son: i) la igualdad en dignidad y derechos con que las personas nacen (inciso primero del artículo $1^{\circ}$ de la Constitución), ii) la igualdad de oportunidades como derecho de las personas en la participación en la vida nacional (inciso quinto del artículo $1^{\circ}$ de la Ley Fundamental), iii) la igualdad ante la ley entre el hombre y la mujer (oración final del inciso primero del número $2^{\circ}$ del artículo 19 de la Constitución), y iv) la igualdad de acceso a las acciones de salud (inciso segundo del número $9^{\circ}$ del artículo 19 de la Constitución)" (sentencia rol $\mathrm{N}^{\circ}$ 1273, considerando 72).

iv. La imposibilidad de costear las alzas de planes es un atentado al derecho a elegir entre el sistema público y el sistema privado de salud. Los votos de mayoría agregan que el art. $19 \mathrm{~N}^{\circ} 9$ es también base constitucional y de orden público del contrato de salud, lo que incluye, por ende, el derecho a elegir el sistema de salud al que la persona desea acogerse. Este derecho se ve afectado cuando se producen alzas en el contrato de salud que impidan seguir costeándolo, y obligan al contratante a emigrar del sistema privado al público o a cambiar de Isapre (sentencias roles $\mathrm{No}_{\text {s. }} 976$, considerando $63^{\circ} ; 1218$, considerando $61^{\circ}$; 1273 , considerando $77^{\circ} ; 1287$, considerando $66^{\circ}$, y 1710 , considerando $155^{\circ}$, respectivamente).

Estas consideraciones llevan a concluir que una persona tiene derecho a permanecer en el plan de salud que contrató con la Isapre, aun cuando no pueda seguir costeándolo en el futuro. En tal sentido, la Isapre es sujeto de lo que podría llamarse una "obligación subsidiaria", derivada del deber de respetar y promover los derechos constitucionales, y del efecto horizontal de éstos, incluidos los derechos sociales, entre los que se cuenta el derecho a la protección de la salud del art. 19 No 9.

v. La posibilidad de establecer diferencias de precios en los contratos de salud en razón de edad y de sexo, y la imposibilidad de costear las alzas de planes de salud, atenta contra el derecho a la seguridad social. La posición de mayoría de los fallos tantas veces mencionados es coincidente también en este punto. Sostiene que aun cuando no se señalen expresamente en el art. $19 \mathrm{~N}^{\circ} 18$, forman parte integrante 
del derecho a la seguridad social, como "principios rectores", la universalidad (subjetiva y objetiva), la integridad o suficiencia, la solidaridad y la unidad (considerandos $26^{\circ}$ al $30^{\circ}$, rol $\mathrm{N}^{\circ} 1218 ; 26^{\circ}$ a $30^{\circ}$, rol $\mathrm{N}^{\circ} 1287 ; 131^{\circ}$ al $133^{\circ}$ y $135^{\circ}$, rol $\mathrm{N}^{\circ} 1710$ ). Por tal razón, la existencia misma de reajustes periódicos del precio del plan de salud previsional sólo por el aumento de edad sería inconstitucional, por atentar contra el derecho a la seguridad social consagrado en el art. $19 \mathrm{~N}^{\circ} 18$ de la Constitución, "precepto que obliga al Estado a asegurar el acceso de todos los habitantes al goce de prestaciones básicas uniformes y a supervigilar el adecuado ejercicio de ese derecho (considerandos $62^{\circ}$, rol $\mathrm{N}^{\circ} 1218$; $67^{\circ}$, rol $\mathrm{N}^{\circ} 1287 ; 78^{\circ}$, rol $\mathrm{N}^{\circ} 1273$ ). A juicio del Tribunal Constitucional, esa uniformidad exigida por la Constitución "resulta vulnerada si el costo de las cotizaciones para la asegurada por el disfrute de unas mismas prestaciones, se ve acrecentado por el mero hecho de progresar en edad, lo que al mismo tiempo produce, como natural efecto, el menoscabo del ejercicio adecuado de su derecho a la seguridad social" (considerando $79^{\circ}$, rol $\mathrm{N}^{\circ} 1273$ ).

\section{b) Problemas que plantea la posición de mayoría}

Puede pensarse que una razón importante para la diferencia de criterios entre la Corte Suprema y el Tribunal Constitucional, radica en la distinta naturaleza de los procedimientos que conocen ambos tribunales: el recurso de protección es un procedimiento de tutela de derechos constitucionales, en tanto que los de competencia del Tribunal Constitucional implican el control de constitucionalidad de preceptos legales. Así, la Corte Suprema resuelve casos concretos en que están en juego derechos constitucionales (art. 20). Por su parte, el Tribunal Constitucional verifica que la aplicación de un precepto legal en un caso concreto no sea inconstitucional (art. $93 \mathrm{~N}^{\circ} 6$ ) y, en su caso, expulsa dicho precepto del ordenamiento jurídico por ser contrario a la Constitución (art. 93 N 7). Por eso, los criterios jurisprudenciales emanados de ambos tribunales podrían entenderse como no extrapolables, pues no es lo mismo resolver casos concretos que controlar normas.

Sin embargo, el problema de fondo es otro: la determinación de la naturaleza, eficacia y valor de un derecho no depende de declaraciones o teorías, sino que de la realidad. Más concretamente, saber si algo es o no un derecho en sentido jurídico depende de su justiciabilidad, en el sentido de acción conducente a una decisión que permitirá amparar y proteger tal derecho frente a las acciones u omisiones de terceros. En tal sentido, la jurisprudencia judicial ordinaria lleva la ventaja. Al respecto no puede pasarse por alto que la jurispru- 
dencia española citada en este trabajo emana de un Tribunal Constitucional, que tiene competencia tanto para controlar la constitucionalidad de las leyes como para dar amparo a los derechos constitucionales. Y si bien en los casos citados proclamó que todos los derechos consagrados en la Constitución son derechos y tienen el mismo valor, a la hora de resolver no pudo sustraerse de la realidad. Más aún, en la sentencia 172/1989 después de proclamar la eficacia directa e inmediata de la Constitución, a continuación sostiene que no le resultan aplicables esas cualidades al derecho de los presos a un puesto de trabajo y a la seguridad social.

Sin perjuicio de lo anterior, si bien la posición de mayoría de las sentencias de nuestro Tribunal Constitucional conlleva darle a los derechos sociales una eficacia similar a la de los clásicos, lo cierto es que buena parte de la argumentación que la sustenta presenta diversos problemas que no se pueden soslayar.

i. El derecho a la salud no es homologable al derecho a la vida. Como se vio antes, las sentencias del Tribunal Constitucional se apartan de manera evidente del criterio de la Corte Suprema, que entiende que no existe directa relación entre el derecho a la vida y el derecho a la protección de la salud. En mi opinión, la posición de la primera resulta más acorde a la naturaleza de ambos derechos. Así, el derecho a la vida es una facultad para exigir la protección de la vida frente a agresiones ilegítimas, lo que incluye el derecho a defender la propia vida y el derecho a nacer. Se trata, por tanto, de un derecho de defensa frente a atentados contra la $v \operatorname{vida}^{40}$. En otros términos, si se aplica la visión del Tribunal Constitucional puede reconducirse el derecho a prestaciones de salud al derecho a la vida y, por ende, hacer justiciable aquél. Se pasa por alto el hecho de que ambos forman parte de numerales distintos del art. 19, y sólo el segundo tiene expresamente la garantía jurisdiccional del recurso de protección.

ii. La errónea interpretación del principio de subsidiariedad y del efecto horizontal de los derechos. La forma en que los votos de mayoría han entendido la subsidiariedad resulta no sólo discutible, pues altera el sentido de este principio, sino que además es peligrosa. Ello, porque transforma a los particulares en obligados servidores de tareas que la Constitución y las leyes atribuyen al Estado, cuando éste no puede cumplirlas, so pretexto de un presunto efecto horizontal de los

\footnotetext{
${ }^{40}$ En verdad la vida no es un derecho, sino que mucho más que eso: es el fundamento de los derechos. Al respecto Pereira Menaut señala acertadamente que la vida, junto a la dignidad, la libertad y la igualdad no son derechos, sino lo que él denomina realidades pre-jurídicas. Con ello quiere aludir a que se trata de hechos que constituyen cualidades inherentes al ser humano, que simplemente se tienen, pues forman parte de nuestra propia naturaleza. Por ende, están fuera del ámbito de lo adjudicable. Pereira (1997), 371.
} 
derechos sociales ${ }^{41}$. Ello conduce a la mayoría a concluir que existiría un derecho a permanecer para siempre en el plan de salud que se contrató ${ }^{42}$.

El problema es que por esta vía se quiere llevar a transformar en deberes jurídicos la solidaridad y la atención a los más desvalidos. Y si bien no cabe duda de que desde el punto de vista moral es posible sostener la existencia de tales deberes, no parece ni claro ni evidente que éstos puedan también juridificarse y, por ende, que puedan exigirse jurídicamente, a menos que pretenda borrarse toda frontera entre el Derecho y la Moral. Porque si bien existe un punto de conexión entre ambos, que es la idea de justicia, y su concreción como lo justo concreto, no parece suceder lo mismo con la justicia entendida como lo justo social ${ }^{43}$. No se trata de minusvalorar la justicia social ni muchísimo menos, sino simplemente de hacer presente que el Derecho no es la vía directa para conseguirla y, por ende, los

${ }^{41}$ En los votos de minoría de las sentencias roles $\mathrm{N}^{\circ}$ s. 976, 1218, 1273 y 1287, los Ministros Bertelsen, Correa (roles Nos. 976 y 1218) y Colombo (roles Nos. 976, 1218, 1273 y 1287), son contrarios a la idea de efecto horizontal del derecho a la protección de la salud respecto de las Isapres, para lo cual sostienen que las acciones de promoción, protección y recuperación de la salud que contempla la Constitución son un deber del Estado y no de los particulares. Y agregan que dicha obligación "es diversa a los derechos de las personas a permanecer en un plan o más precisamente a mantener inalterable un precio de un seguro destinado a cubrir los costos en que incurran en materia de salud" (considerandos $9^{\circ}, 5^{\circ}, 5^{\circ}$ y $2^{\circ}$, respectivamente). Hay que precisar que en la sentencia rol No1287 no participó el Ministro Bertelsen, y el Ministro Correa ya había cesado en el Tribunal Constitucional, siendo reemplazado por el Ministro Carmona, que concurrió al voto de mayoría en esa sentencia y en la rol No 1273 .

${ }^{42}$ Pero como señala la posición de minoría de las sentencias roles Nº. 1218, 1273 y 1287, "la Constitución no asegura a las personas poder permanecer en un determinado plan o seguro de salud, ni menos a hacerlo por un precio inalterable. La obligación impuesta al Estado -y no a instituciones particulares- de proteger el libre e igualitario acceso a las acciones de promoción, protección y recuperación de la salud, que la Constitución sí establece, es diversa a los derechos de las personas a permanecer en un plan o más precisamente a mantener inalterable un precio de un seguro destinado a cubrir los costos en que incurran en materia de salud. Si bien existe una relación entre aquella obligación -impuesta sólo al Estado-y que dice relación con las acciones de salud y el derecho que se pretende, que se refiere al modo de financiar el acceso a esas acciones de salud, la diferencia entre ambas resulta evidente, tanto desde el punto de vista del sujeto obligado como de la naturaleza de la obligación constitucional y el derecho que se pretende, ya que es distinta una prestación de salud que el seguro destinado a cubrir todo o parte del costo de la misma" (considerandos $5^{\circ}, 5^{\circ}$ y $2^{\circ}$, respectivamente). Y agregan que "No puede sostenerse que la Carta Fundamental que nos rige consagre el acceso igualitario a un seguro de salud, independiente de la capacidad de pago de la persona. Tal independencia entre un bien y su acceso universal e igualitario se ha logrado respecto a ciertas prestaciones de salud, a través del Plan Auge, sistema de gratuidad que la Constitución permite, pero que no hace obligatorio y menos para los contratos con Isapres, que no son prestaciones de salud, sino sistemas para cubrir los riesgos económicos de ese bien" (considerandos $6^{\circ}, 6^{\circ}$ y $3^{\circ}$, respectivamente).

${ }^{43}$ Como dice Pereira, "el derecho es la aplicación de la justicia a los casos concretos, a la realidad. No coincide al ciento por ciento con la justicia; más bien sería la cantidad de justicia posible en el pleito que sea. Su finalidad es solucionar conflictos, no hacer buenos a los hombres -aunque tampoco hacerlos malos: el buen derecho inducirá indirectamente a la gente a comportarse mejor-". Pereira (2010), 59. 
jueces no pueden transformarse en agentes de justicia social, so riesgo de invadir competencias propias de los poderes políticos.

Más allá de lo anterior, no puede pasarse por alto que este mismo razonamiento podría alcanzar, por ejemplo, al derecho de los padres a elegir el establecimiento educacional para sus hijos del art. 19 No 11 inciso $4^{\circ}$ de la Constitución, con el agravante que este derecho tiene amparo jurisdiccional vía recurso de protección. En otros términos, en virtud de las mismas razones antes esbozadas, unos padres podrían sostener que tienen derecho a que su hijo permanezca en el establecimiento educacional en el que estudia, porque fue el elegido por ellos, aunque con posterioridad no pudieran pagarlo.

Todo ello es sin perjuicio de que, en virtud del principio de subsidiariedad, el Estado puede cumplir a través de particulares con los deberes que le impone la Constitución y las normas dictadas conforme a ella. Así lo ha reconocido expresamente el Tribunal Constitucional en su sentencia rol $N^{\circ} 1138$, al señalar que "el Estado puede cumplir sus obligaciones a través de los particulares, en conformidad al principio de subsidiariedad o supletoriedad. Pero ello no puede suponer un detrimento patrimonial para el particular al que el Estado efectuó el encargo, razón por la cual aquéllos deben ser debidamente retribuidos (considerando $51^{\circ}$; y en los mismos términos la sentencia rol $N^{\circ} 1140$, considerando $45^{\circ}$ y sentencia rol $\mathrm{N}^{\circ}$ 1254, considerando 77).

iii. La protección del derecho a la salud de quienes interpusieron los requerimientos de inaplicabilidad genera una desigualdad. Otro de los problemas de las sentencias aquí analizadas, radica en que, en la práctica, las decisiones del Tribunal Constitucional se han traducido en un tratamiento especial y preferente para las personas recurrentes, por el solo hecho de haber interpuesto los requerimientos de inaplicabilidad. En efecto, las declaraciones de inaplicabilidad sólo beneficiaban a los recurrentes, a pesar de que la aplicación de los factores permitidos por la ley para calcular el precio de los planes de salud establecidos en la ley afectaba sin duda a muchísimas personas que estaban en situaciones similares.

iv. El requerimiento de inaplicabilidad procede contra preceptos legales, y no contra actos administrativos. Otro de los aspectos discutibles de los votos de mayoría de las sentencias de inaplicabilidad, es el hecho de que en la práctica mediante las cuestiones se persiguió encubiertamente inaplicar un acto administrativo y unas modificaciones contractuales, cuestiones ajenas a los objetivos y finalidad de este procedimiento. Como advierte el Ministro Navarro Beltrán, si bien en apariencia se impugna una norma legal, "el cuestionamiento se encuentra también dirigido a las instrucciones impartidas por la Superintendencia de Salud, en las que se fija la estructura de la tabla de factores, lo que debe ser impugnado a través de 
otras vías judiciales, como es el caso de las acciones contencioso administrativas" (sentencias 1218 , considerando $9^{\circ}$ de su disidencia, y 1710 , considerando $37^{\circ}$ de su disidencia).

v. El problema de la separación de poderes y de la deferencia respecto de los poderes políticos. Por otra parte, la posición de mayoría supone, a mi juicio, una infracción al principio de deferencia razonada, que ha sido reconocido y aplicado en otras ocasiones por el propio Tribunal Constitucional (por ejemplo, sentencias roles $\mathrm{No}_{\text {s. }} 706$, considerando 12; 790, considerando 28; 1001, considerando 16; 1129, considerando 6; 1361, considerando 14). En concreto, la posición de mayoría ha supuesto el enjuiciamiento de una legítima opción adoptada por el poder político democráticamente elegido. Al respecto, los votos de minoría de la sentencia rol $N^{\circ} 976$ destacan que es competencia del legislador la adopción de políticas sociales que permiten el ejercicio de derechos constitucionales, y que si bien dichas regulaciones pueden ser perfectibles, esto no es tarea de los jueces. Ello, porque, a su juicio, "no es tarea de esta Magistratura enjuiciar cuán equitativo resulta que los particulares produzcan y provean bienes esenciales, tampoco que el legislador haya decidido que el sistema privado de Isapres, siempre voluntario para el usuario, no contenga reglas de solidaridad, más allá de la típica de los seguros" (considerando $15^{\circ}$ ).

En este mismo sentido, el Ministro Colombo, en su voto disidente en la sentencia rol $\mathrm{N}^{\circ} 1287$, sostiene que "la introducción, entonces, de fórmulas solidarias de carácter general en el financiamiento de las contingencias derivadas de los riesgos cubiertos por la seguridad social, es únicamente de competencia del legislador y no es una exigencia establecida en la Carta Fundamental que corresponda controlar al Tribunal Constitucional" (considerando $5^{\circ}$ ).

Pero, además, en la sentencia rol No 976 los disidentes acuden a una argumentación nada despreciable desde la óptica de la teoría constitucional, a saber, la necesidad de respetar el principio de separación de poderes y, en concreto, la autonomía del legislador. En tal sentido sostienen que "el alza que produce en los costos de salud el envejecimiento de las personas es un hecho inevitable. Así, no estamos llamados por esta vía a juzgar la sabiduría del resultado que han producido tales opciones políticas y hechos inevitables, cual es de que el legislador, dentro de ciertos márgenes, permita al proveedor de seguros de salud alzar los precios de ellos sin consentimiento de su contraparte. Todas esas decisiones ya fueron adoptadas por el legislador, quien autorizó expresamente a esas entidades a subir esos precios, sin la voluntad del afiliado. Consta en el debate de la ley impugnada que, para decidir del modo en que lo hizo, tuvo presente un conjunto de consideraciones relativas a la variación de los costos de la salud, mercados de seguros 
y desarrollo nacional, que corresponden típicamente a un análisis de mérito que el sistema democrático que nos rige radica en el legislador y que este Tribunal no está llamado a revisar y menos a sustituir. Tampoco está llamado este Tribunal a juzgar si las específicas alzas que ha padecido la requirente se ajustan o no a la ley, pues ello es tarea de los jueces del fondo". Finaliza el voto disidente señalando que los jueces no son competentes para "determinar en cada caso que se nos presenta, cuál sea la contribución equitativa que cada proveedor de bienes y servicios debe hacer al goce de los derechos constitucionales de los usuarios". Ello, porque si los precios de bienes y servicios fuesen determinados de manera particular, en base a la "equidad de cada caso, se haría imposible para los particulares llamados a proveer esos servicios proyectar o calcular las ganancias que el sistema les autoriza y que constituye el aliciente de su participación". Así, si no hay "antecedentes claros que determinen que el legislador ha infringido la Constitución al establecer las bases para la fijación de los precios, no es tarea de los jueces alterarlos" (considerandos $15^{\circ}$ y $\left.16^{\circ}\right)$.

En resumen, no parece competerle a los jueces analizar si es o no más conveniente contar con un sistema de protección de salud más solidario.

vii. La posición de mayoría supone fallar el fondo y, por ende, inmiscuirse en competencias propias de los jueces del fondo. Como advierte en sus disidencias el Ministro Navarro, en los casos se estaba en presencia de solapadas impugnaciones al actuar de empresas privadas, las Isapres, materia que estaba siendo conocida en sedes judiciales y que, por ende, no era de competencia del Tribunal Constitucional. De esta forma, acoger las inaplicabilidades supone en la práctica inmiscuirse en el enjuiciamiento de fondo, a saber, si la actuación de las Isapres ha sido o no legítima, en el sentido de si los ajustes han sido o no abusivos.

viii. El problema del lenguaje de los valores. Otro de los problemas que plantea la posición de mayoría es el relativo al rol de los valores en el sistema constitucional. La opinión mayoritaria entiende que tanto los poderes públicos como las personas están obligadas no sólo a los preceptos de la Constitución, sino que además a los valores contemplados en ella, los que disfrutarían de la misma supremacía que las normas constitucionales (considerandos $25^{\circ}, 19^{\circ}$ y $19^{\circ}$ de las sentencias roles $\mathrm{No}^{\circ}$. 976, 1218 y $\left.1287^{44}\right)$. Independientemente de lo difícil que resulta definir

\footnotetext{
${ }^{44}$ En las sentencias roles $\mathrm{N}^{\circ}$ s. 1273 y 1710 el Tribunal Constitucional se aparta un poco de la posición de los otros fallos, ya que más que hablar de valores, argumenta sobre la base de la dignidad de la persona, a la que le atribuye el carácter de principio y norma (considerandos $46^{\circ}$ y $48^{\circ}$, respectivamente). Esta argumentación se funda en la visión de Pereira Menaut acerca de la dignidad de la persona (sentencia rol No 1273, considerando 44), a las que junto con la vida, la libertad y la igualdad, califica de realidades pre-jurídicas. El problema está en que para Pereira las realidades pre-jurídicas son eso y no principios, ni menos normas. Para un análisis respecto de lo que él entiende por valores, principios y normas ver su Teoría Constitucional, 315 y ss.
} 
qué es un valor, lo cierto es que, como señala Pereira, esta es una temática más filosófica que jurídica ${ }^{45}$. No se trata de negar la existencia de alguna relación entre el Derecho y la Política con los valores, pero no parece claro que el lenguaje de los valores sirva para resolver litigios, porque no ayudan a concretar, sino más bien a la argumentación abstracta y retórica. Pereira advierte que "el Derecho tiene un trasfondo de valores -...-, pero eso es distinto de 'consistir en' valores como 'consiste en' sentencias, leyes y principios". Y es que una cosa es partir de unos ciertos presupuestos valorativos que "adjudicar valores o introducir en la adjudicación un discurso deliberadamente valorativo" 46 .

Más aún, como lo demuestran los fallos que se han analizado en este trabajo, el lenguaje de los valores puede llevar incluso a imponer comportamientos morales a las personas, por ejemplo, obligarlas a ser solidarias. Es evidente que la solidaridad es algo bueno y deseable en sí mismo, pero resulta al menos discutible que pueda transformarse en una obligación jurídica. Además, este enfoque constitucional puede llevar a la paradoja de que bajo el pretexto de promover valores, se amplíe la actuación del poder en detrimento de los derechos y libertades. O como sucedió en estas sentencias, puede llegarse a imponer a privados el cumplimiento de funciones y deberes propios del Estado.

$i x$. Dar por sentado que la ponderación es la única forma de resolver conflictos $o$ choques de derechos. En la sentencia rol $\mathrm{N}^{\circ} 1710$, el voto de minoría se hace cargo del conflicto existente entre los derechos constitucionales de los involucrados en el conflicto. Para ello acude a la doctrina alemana, y en particular a la posición de Robert Alexy, a partir de lo cual concluye que la forma de resolver aquel conflicto es mediante el criterio de ponderación (considerandos $92^{\circ}$ y $93^{\circ}$ ). No cabe duda de que la doctrina alemana y el referido autor han tenido gran influencia en Hispanoamérica, y es indudable también el alto nivel intelectual y teórico que ahí puede encontrarse.

Sin embargo, el voto de mayoría olvida que la visión alemana del Derecho Constitucional y de los derechos no es la única, ni es la que se corresponde con los orígenes y sentido del Derecho Constitucional y de la Constitución ${ }^{47}$. Más

\footnotetext{
45 Pereira (2006), 320.

${ }^{46}$ Ibid., p. 322. El mismo Pereira sostiene acertadamente que como los valores "encajan mal en el razonamiento jurídico pueden distorsionar la interpretación y aplicación del derecho. Introducen elementos de juicio no jurídicos, a veces abiertamente ideológicos; aumentan la inseguridad y amenazan el normal desenvolvimiento de la adjudicación en el caso concreto, porque no buscan dar a cada uno lo suyo sino promover un valor. Como dice Richard Stith, los valores no proponen procedimientos sino metas (y no siempre jurídicas), por lo que tienden a prestar poca atención a cómo se alcanzan esas metas. Lo contrario, por tanto, del razonamiento jurídico". Pereira (2010), pp. 62-63.
}

${ }^{47}$ Ver nota 39. 
aún, en materia de conflictos o choques de derechos existen al menos otros dos criterios: el de jerarquización y el de determinación del contenido esencial ${ }^{48}$. No se trata de resolver aquí cuál es el mejor, sino simplemente de hacer presente que no se puede dar por supuesto que la única forma de resolver choques de derechos es la utilizada en este caso por el Tribunal Constitucional, como si se tratase de un tema pacífico.

\section{VII. ¿CÓMO PROTEGER LOS DERECHOS SOCIALES?}

Como se ha visto hasta aquí, el problema de gran parte de los derechos sociales es que sólo consisten en mandatos al Estado, particularmente al legislador, debido a que en su mayoría suponen prestaciones. Ello impide considerarlos derechos (en sentido jurídico estricto). Se trata más bien de preceptos meramente programáticos; son exhortaciones a los poderes públicos a las que éstos no quedan obligados. Sólo se transforman en verdaderas exigencias jurídicas cuando se recogen en disposiciones infraconstitucionales.

Distinta es la situación de aquellos que no suponen prestaciones, como ocurre con los derechos colectivos laborales, o incluso el derecho a vivir en un ambiente libre de contaminación. Se trata de facultades cuyo reconocimiento constitucional puede ir perfectamente acompañado de garantías jurisdiccionales, pues son facultades de naturaleza justiciable. Y entonces, ¿¿de qué sirve la constitucionalización de derechos sociales que consisten en prestaciones? Una posible respuesta está en considerarlos garantías institucionales, aunque como se verá más adelante, ello está igualmente sujeto a límites.

\section{A) Los derechos sociales como garantías institucionales}

Los preceptos sobre derechos sociales consistentes en prestaciones son normas políticas, directrices y principios orientadores del fin del constitucionalismo social, que no es otro que lograr la igualdad material. A lo más podrían adquirir algún sentido jurídico si se les considerase garantías institucionales, como hacen algunos autores ${ }^{49}$. Entonces, los derechos sociales de prestación serían institutos jurídicos, más que político-sociales, pues el concepto de garantías institucionales fue inventado para amparar tales institutos frente al legislador. Pero, por lo dicho

\footnotetext{
${ }^{48}$ Sobre los diversos métodos de solución de conflictos pueden de derechos consultarse, entre otros, SERNA (1994); De Otto (1998); Cianciardo (2000); Serna y Toller (2000); Bertelsen (2008).

${ }^{49}$ Cruz (1993), 103 y ss. De Otto (1987), 48.
} 
hasta aquí, queda claro que esta clase de derechos no tienen un sentido jurídico, sino político-social, por lo que sólo pueden entenderse como instituto políticosocial. De ahí que la propuesta de aquellos autores sólo puede considerarse si se reinterpreta el concepto de garantía institucional, dando cabida en él no sólo a institutos jurídicos sino también políticos. En tal caso, el legislador no podría adoptar medidas que supusieran la derogación o eliminación tácita de los derechos sociales consagrados en la Constitución. De hacerlo, tal medida podría ser impugnada a través de los mecanismos de control abstracto de constitucionalidad que contemple cada Constitución, lo que no es poco.

Todo esto debe ser entendido sin perjuicio de la libertad del legislador para poner en práctica y desarrollar los derechos sociales consistentes en prestaciones. En dicha labor no está sujeto a ningún tipo de limitaciones, ni siquiera a aquella que algunas constituciones, como la española o la chilena, denominan "contenido esencial de los derechos". Y la razón es simple: los derechos sociales de tipo prestacional no tienen contenido esencial. Su propia naturaleza lo impide, ya que el contenido del derecho será lo que el legislador determine en cada caso. No obstante, es evidente que en todo caso el desarrollo legislativo de los derechos sociales estará sujeto al general respeto del principio de igualdad, lo que hará posible el control de constitucionalidad de los preceptos que atentasen contra el mismo.

\section{B) Limites al control de constitucionalidad en materia de derechos sociales consistentes en prestaciones}

A pesar de lo que pudiera desprenderse de los fallos de nuestro Tribunal Constitucional, creo que, como sostiene de Otto, el control de constitucionalidad basado en los preceptos que los consagran está sujeto a límites. Y es que "si se pudiera enjuiciar la adecuación entre la ley y el fin constitucionalmente prescrito -por ejemplo, si una ley es o no adecuada al fin de procurar a todos una vivienda digna (art. 47) - el Tribunal Constitucional estaría suplantando al legislador en su función estrictamente política de elegir los medios conducentes a un fin. El respeto a la posición de la ley en el ordenamiento jurídico [...] exige que el Tribunal Constitucional se limite a sancionar la infracción frontal del mandato, esto es, aquellos supuestos en que la ley resulte manifiesta y claramente contraria al fin prescrito" 50 .

\footnotetext{
${ }^{50}$ De Отто (1987), 48. Esta posición es similar a la esbozada en los considerandos 15 y 16 del voto de minoría de los Ministros Correa, Bertelsen y Colombo en la sentencia rolo 976.
} 
Si las garantías institucionales amparasen no sólo institutos jurídicos sino también políticos, los derechos sociales consistentes en prestaciones no estarían del todo desamparados frente al legislador. Se dijo antes que los derechos sociales pueden considerarse institutos político-sociales, con lo que se cumpliría el supuesto anterior y, por tanto, el legislador no podría eliminar o derogar tales derechos, ni expresa ni tácitamente. De hacerlo, se podría ejercer control de constitucionalidad de la legislación infractora.

Cabe preguntarse si el legislador podría revocar o alterar sustancialmente el contenido de un derecho social, después de haber sido éste dotado de contenido. Si dicha actuación legislativa se diese en relación a los derechos colectivos laborales no habría mayor problema, ya que en ningún caso impediría el ejercicio de tales derechos. Se trata de manifestaciones de libertad, y como tales se bastan a sí mismas, por lo que podrían ejercerse aun cuando el legislador derogue o modifique sustancialmente las normas que los regulen.

Distinta es la situación de los derechos sociales consistentes en prestaciones, pues se trata de derechos de configuración legal. Por eso el legislador es libre para desarrollarlos y dotarlos de contenido cierto, así como para modificar dicho desarrollo y contenido cuando lo estime necesario.

\section{C) Una alternativa: el control del respeto a los derechos sociales de prestación por un organismo no jurisdiccional}

A pesar de todo lo dicho hasta aquí, es un hecho que muchas constituciones reconocen derechos sociales, incluidos los consistentes en prestaciones. De ahí que parece sensato preguntarse qué hacer con ellos una vez constitucionalizados. Su no eficacia jurídica ¿significa que no puede dotárseles de algún mecanismo de tutela? Una respuesta interesante para ambas preguntas la dan Pereira y Sánchez ${ }^{51}$, quienes plantean la posibilidad de crear un órgano independiente, con funciones consultivas y de asesoramiento en materias político-sociales, que pudiera vetar las leyes o políticas manifiestamente antisociales. Creo que esta opción resulta aceptable, aunque debe reconocerse que a veces la situación económica de un país, puede conducir al sacrificio de algunas conquistas sociales para el mantenimiento de otras de mayor entidad. En pocas palabras, creo que si bien es posible defender el "principio de irreversibilidad de las conquistas sociales", debe existir la necesaria flexibilidad que permita acomodar las políticas sociales a las circunstancias económicas de cada momento.

${ }^{11}$ Pereira y SÁnchez (1992), pp. 269-272. 


\section{BiBLIOGRAFÍA}

Abramovich, Víctor y Courtis, Christian (2002): Los derechos sociales como derechos exigibles (Madrid, Trotta).

Alonso García, Enrique (1982): “Los 'welfare rigths' y la libertad parlamentaria de ordenación del gasto público: La lucha entre dos principios constitucionales de política socio-económica (Comentarios a la jurisprudencia del Tribunal Supremo norteamericano)", en Revista Española de Derecho Constitucional 4, pp. $155-168$.

ARANGO, Rodolfo (2005): El concepto de derechos sociales fundamentales (Bogotá, Legis).

AtriA, Fernando (2004): "Réplica: derecho y política a propósito de los derechos sociales”, en Discusiones (año IV No 4), pp. 145-176.

Bernal Pulido, Carlos (2004): "Fundamento, concepto y estructura de los derechos sociales. Una crítica a ‘Existen derechos sociales?' de Fernando Atria”, en Discusiones (año IV, No 4), pp. 99-144.

Bertelsen SimonetTi, Soledad (2008): Métodos de solución de conflictos entre derechos fundamentales (Santiago, Universidad de los Andes, Memoria para optar al grado de Licenciado en Derecho).

Carbonell, Miguel (2008): "Eficacia de la Constitución y derechos sociales: esbozo de algunos problemas", en Estudios Constitucionales, año 6, № 2, pp. 43-71.

Cascajo Castro, José Luis (1988): La tutela constitucional de los derechos sociales (Madrid, Centro de Estudios Constitucionales).

Cianciardo, Juan (2000): El conflictivismo en los derechos fundamentales (Pamplona, Eunsa).

Contreras Peláez, Francisco J. (1994): Derechos Sociales. Teoría e Ideología (Madrid, Tecnos).

Cruz Villalón, Pedro (1993): "La Ley Fundamental y la unidad de Alemania. Una conversación con Konrad Hesse", Anuario de Derecho Constitucional y Parlamentario 3, pp. 7-28.

Cruz Villalón, Pedro (1993): "Los derechos sociales y el Estatuto de Autonomía”, en Cámara y Cano (Editores), Estudios sobre el Estado Social y la Comunidad Autónoma de Andalucía (Madrid, Parlamento de Andalucía-Tecnos), pp. 103 y ss.

De Отто, Ignacio (1987): Derecho Constitucional. Sistema de Fuentes (Barcelona, Ariel). 
De Oтто, Ignacio (1988): "La regulación del ejercicio de los derechos y libertades. La garantía de su contenido esencial en el artículo 53.1 de la Constitución”, en Martín Retortillo y de Otto, Derechos fundamentales y Constitución (Madrid, Civitas).

Figueroa García-Huidobro, Rodolfo (2009): “Justificación del rol de las Cortes haciendo justiciables los Derechos Económicos, Sociales y Culturales, en particular, el derecho a la protección de la salud", en Revista Chilena de Derecho (vol. 36 No 2), pp. 313-342.

Hesse, Konrad (1992): Escritos de Derecho Constitucional, segunda edición (Madrid, Centro de Estudios Constitucionales).

Jordán DíAz, Tomás Pablo (2008): La protección de los Derechos Sociales: modelos comparados de tutela jurisprudencial (España y Chile) (Santiago, Universidad Alberto Hurtado, Colección de Investigaciones Jurídicas No 10).

Loewenstein, Karl (1976): Teoría de la Constitución, segunda edición (Barcelona, Ariel).

MARTíNez EstaY, José Ignacio (1997): Jurisprudencia constitucional española sobre derechos sociales (Barcelona, CEDECS).

Mayorga LorCa, Roberto (1990): Naturaleza Jurídica de los Derechos Económicos, Sociales y Culturales, segunda edición (Santiago de Chile, Editorial Jurídica).

Nogueira Alcalá, Humberto (2009): Derechos fundamentales y garantías constitucionales. Los derechos sociales fundamentales (Santiago, Centro de Estudios Constitucionales de Chile-Librotecnia).

Nogueira Alcalá, Humberto (2009): "Los derechos económicos, sociales y culturales como derechos fundamentales efectivos en el constitucionalismo democrático latinoamericano", en Estudios Constitucionales (Año 7, N²), pp. 143-205.

Paiva Ziti Afonso, Lidia (2009): "A efetividade dos direitos fundamentais sociais pela Corte Interamericana de Direitos Humanos (Caso Brasil)", en Revista da Faculdade de Direito do Sul de Minas (año XXV, No 28), pp. 207-226.

Palmer, Ellie (2007): Judicial review, socio-economic rigths and the Human Rigths Act (London, Hart Publishing).

Peces-Barba, Gregorio (1980): Los Derechos Fundamentales (Madrid, Latina).

Pereira Menaut, Antonio Carlos y Sánchez González, Santiago (1992): "Los derechos sociales y los principios rectores de la política social y económica”, en Revista de Derecho Político (No 36), pp. 257-276.

Pereira Menaut, Antonio Carlos (1997): Lecciones de Teoría Constitucional, tercera edición (Madrid, Colex). 
Pereira Menaut, Antonio Carlos (2006): Teoría Constitucional, segunda edición (Santiago, LexisNexis).

Pereira Menaut, Antonio Carlos (2010): Politica y Derecho (Santiago, Abeledo Perrot).

PISARELlo, Gerardo (2007): Los derechos sociales y sus garantías: elementos para una reconstrucción (Madrid, Trotta).

Schmiтt, Carl (1982): Teoría de la Constitución (Madrid, Alianza).

Serna, P. (1994): "Derechos fundamentales: el mito de los conflictos. Reflexiones teóricas a partir de un supuesto jurisprudencial sobre intimidad e información”, en Humana Iura ( $\mathrm{N}^{\circ}$ 4), pp. 197-234.

Serna, P. y TOlLer, F. (2000): La interpretación constitucional de los derechos fundamentales. Una alternativa a los conflictos de derechos (Buenos Aires, La Ley).

Tavares, André (2006): Curso de Direito Constitucional, cuarta edición (San Pablo, Editora Saravia).

\section{JURISPRUDENCIA CITADA}

Airey v. Ireland (1979): Tribunal Europeo de Derechos Humanos, 9 de octubre de 1979.

Sentencia 77/1985, de 27 de junio: Tribunal Constitucional de España, en: http:// www.boe.es/aeboe/consultas/bases_datos/doc.php?coleccion=Tribunal Const itucional\&id=SENTENCIA-1985-0077

Sentencia 134/1987, de 21 de julio: Tribunal Constitucional de España, en: http:// www.boe.es/aeboe/consultas/bases_datos/doc.php?coleccion=Tribunal Const itucional\&id=SENTENCIA-1987-0134

Sentencia 90/1989, de 11 de mayo: Tribunal Constitucional de España, en: http:// www.boe.es/aeboe/consultas/bases_datos/doc.php?coleccion=Tribunal Const itucional\&id=SENTENCIA-1989-0090

Sentencia 172/1989, de 19 de octubre: Tribunal Constitucional de España, en: http://www.boe.es/aeboe/consultas/bases_datos/doc.php?coleccion=Tribunal Constitucional\&id=SENTENCIA-1989-0172

Sentencia 17/1993, de 18 de enero: Tribunal Constitucional de España, en: http:// www.boe.es/aeboe/consultas/bases_datos/doc.php?coleccion=Tribunal Const itucional\&id=SENTENCIA-1993-0017

Auto 256/1988, de 29 de febrero: Tribunal Constitucional de España, en: http:// www.boe.es/aeboe/consultas/bases_datos/doc.php?coleccion=Tribunal Const itucional\&id=AUTO-1988-0256 
Auto 95/1989, de 20 de febrero: Tribunal Constitucional de España, en: http:// www.boe.es/aeboe/consultas/bases_datos/doc.php?coleccion=Tribunal Cons titucional\&id=AUTO-1989-0095

Zelman v. Simmons, 536 U.S. 639 (2002): Corte Suprema de los Estados Unidos de Norteamérica.

Parents Involved in Community Schools v. Seattle School District No. 1 et al 551 US (2007): Corte Suprema de los Estados Unidos de Norteamérica.

Fullilove v. Klutznick 448 U.S. 448 (1980): Corte Suprema de los Estados Unidos de Norteamérica.

Sepúlveda Parías con Subdirector del Hospital Barros Luco-Trudeau (1987): Corte Suprema, 28 de diciembre de 1987, en: http://cl.microjuris.com/geTribunal Constitucionalontent?reference=MJCH_MJJ3580\&links=[GRAC].

Gallardo Soto con Servicio de Salud Metropolitano Oriente (1988): Corte Suprema, 29 de enero de 1988, en: Gaceta Jurídica 91, pp. 11-14.

Colegio Médico de Chile AG (Consejo Regional Valparaíso) con Secretario Regional Ministerial de Salud de Valparaiso y Director del Servicio de Salud Viña del Mar -Quillota (2001): Corte Suprema, 5 de marzo de 2001, en: http://www. poderjudicial.cl/causas/esta402.php? rowdetalle=AAANoPAAOAABUFkAAI consulta $=100 \&$ glosa $=\&$ causa $=692 / 2001 \&$ numcua $=2583 \&$ secre $=$ UNICA

Rojas Vera y otros con Servicio de Salud Metropolitano Oriente y Ministerio de Salud (2001): Corte Suprema, 9 de octubre de 2001, en: http://www.poderjudicial. $\mathrm{cl} /$ causas/esta402.php? rowdetalle=AAANoPAAMAABPgQAAK\&consulta=1 $00 \&$ glosa $=\&$ causa $=3599 / 2001 \&$ numcua $=15996 \&$ secre $=$ UNICA

Ossa Aránguiz con Ministerio de Salud, Servicio de Salud del Maule y Servicio de Salud Metropolitano Norte (2002): Corte Suprema, 26 de marzo de 2002, en: Gaceta Jurídica 261, pp. 29 y ss.

Marcell Chacón con Servicio de Salud Metropolitano Occidente (2009): Corte Suprema, 16 de diciembre de 2009, en: http://www.poderjudicial.cl/causas/ esta402.php? rowdetalle=AAANoPAANAACulCAAC \& consulta=100\&glosa $=\&$ causa $=8513 / 2009 \&$ numcua $=44087 \&$ secre $=$ UNICA

Rol No 976 (2008): Tribunal Constitucional de Chile, 26 de junio de 2008, en: http://www.tribunalconstitucional.cl/index.php/sentencias/download/ $\mathrm{pdf} / 957$

Rol No 1218 (2009): Tribunal Constitucional de Chile, 7 de julio de 2009, en: http://www.tribunalconstitucional.cl/index.php/sentencias/download/ pdf/1182 
Rol N 1287: Tribunal Constitucional de Chile, 8 de septiembre de 2009, en: http://www.tribunalconstitucional.cl/index.php/sentencias/download/ $\mathrm{pdf} / 1219$

Rol No 1273: Tribunal Constitucional de Chile, 20 de abril de 2010, en: http:// www.tribunalconstitucional.cl/index.php/sentencias/download/pdf/1335

Rol No 1710: Tribunal Constitucional de Chile, 6 de agosto de 2010, en: http:// www.tribunalconstitucional.cl/index.php/sentencias/download/pdf/1479 